University of Rhode Island

DigitalCommons@URI

Open Access Dissertations

1999

\title{
Observed Conflict, Sexual Experience, Pornography, and Coercive Behavior as Predictors of Men's Sexual Arousal to Sexual and Violent Images
}

James Allen Miller

University of Rhode Island

Follow this and additional works at: https://digitalcommons.uri.edu/oa_diss

\section{Recommended Citation}

Miller, James Allen, "Observed Conflict, Sexual Experience, Pornography, and Coercive Behavior as Predictors of Men's Sexual Arousal to Sexual and Violent Images" (1999). Open Access Dissertations. Paper 986.

https://digitalcommons.uri.edu/oa_diss/986

This Dissertation is brought to you for free and open access by DigitalCommons@URI. It has been accepted for inclusion in Open Access Dissertations by an authorized administrator of DigitalCommons@URI. For more information, please contact digitalcommons-group@uri.edu. 
OBSERVED CONFLICT, SEXUAL EXPERIENCE, PORNOGRAPHY, AND COERCIVE BEHAVIOR AS PREDICTORS OF MEN'S SEXUAL AROUSAL TO SEXUAL AND VIOLENT IMAGES

\section{BY}

JAMES ALLEN MILLER

A DISSERTATION SUBMITTED IN PARTIAL FULFILLMENT OF THE REQUIREMENTS FOR THE DEGREE OF DOCTOR OF PHILOSOPHY

IN

PSYCHOLOGY

\#3289572

UNIVERSITY OF RHODE ISLAND 


\section{ABSTRACT}

This study investigated predictors of sexual arousal to erotic, rape, and non-sexual violent videotaped stimuli in a sample of 82 undergraduate men. Questionnaire self-report measures of observed parental conflict, conflict tactics practiced in interpersonal relations, coercive sexual behavior, variety of sexual experiences, and frequency of using various forms of pornography, as well as a number of relevant demographic measures like fraternity affiliation, athletic participation, frequency of intercourse, and number of sexual partners, were assessed. These measures were used in analyses that tested relationships among these variables and determined group differences based on dichotomized classification of high and low scores.

Subsequently, in the experimental segment of the study, videotaped excerpts from commercial films were presented depicting images of erotica, rape, and non-sexual violence while participants provided a continuous lever-adjusted rating of their perceived sexual arousal and simultaneous continuous physiological measurements were recorded of their penile tumescence.

Statistical analyses confirmed the prediction of association between observed aggression and violence and practiced aggression and violence, especially at higher levels. In terms of coercive sexual behavior, one man in five admitted using such tactics to gain sexual access to reluctant partners, and, in fact, this sample included a sizeable number of admitted rapists. When the particular order of presentation of the stimuli was examined, it seemed that prior exposure to both erotic and rape videos seriously degraded the participant's 
arousal to the violent video that followed. Arousal was most enhanced by prior exposure to the erotic video alone, but collectively, either order of presentation that began with the violent video, without any other sexual or sexually aggressive stimulus prime, resulted in the greatest arousal.

Sexual arousal to the rape stimulus was best predicted by the single element of athletic involvement, i.e., membership in varsity teams, especially football or basketball. For non-sexual violent images, the strongest combination of predictors for sexual arousal was the combination of being a varsity athlete, having observed more frequent severe violence between parents, and being younger than the average participant.

Implications are evident not only for rape prevention and batterers' programs, but also for the design of family intervention strategies. 


\section{ACKNOWLEDGMENTS}

l'd like to thank my committee and members of the department for their help and direction over the past years. I'd also like to thank John Lamberti, the editing wizard, for a set of magnificent stimuli and Jim Tillinghast, polygraph technician extrordinaire, for all of his help in the lab. Special thanks are also in store for Dr. Joan Lausier for meeting the last-minute challenge of directing my defense and for Dr. Janet Hirsch, mentor, model, and friend.

Most of all, I'm grateful to my family for their support and encouragement throughout this entire process: for my children Michael, Peter, Christy, Marc, and Matthew, who cheered me on, even when I was most overwhelmed, and for my wife Dr. Jean Dietrich, who has always been, and will always be, my inspiration, my motivation, my solace, and my life-long love. 


\section{TABLE OF CONTENTS}

Acknowledgements iv

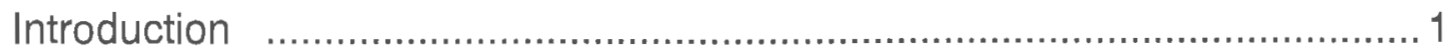

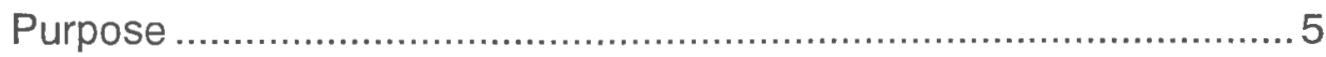

Witnessing Parental Aggression and Violence ................................... 6

Sexual Dynamics of Aggressive Behavior ......................................... 9

Sexual Experience and Aggression............................................. 12

Psychophysiological Reactions and Sex Experience ....................... 13

Pornography's Effect on Aggressive Behavior................................. 15

The Interaction of Physiological Responses and Cognitive Appraisals16 Physiological and Subjective Measures of Sexual Arousal ............... 18

Correlates of Sexual Aggression ................................................... 19

Summary and Study Hypotheses ................................................20

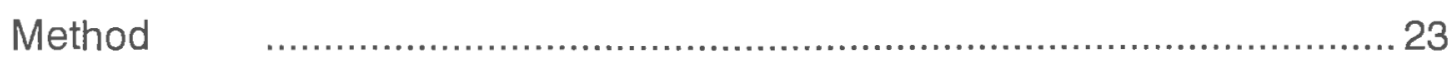

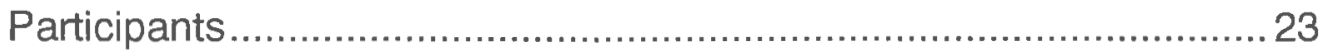

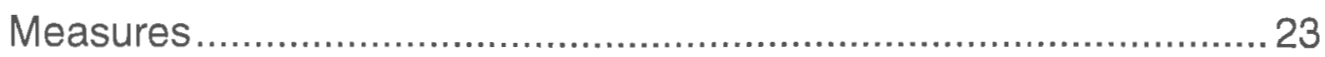

Demographic data and relevant activities ............................ 23

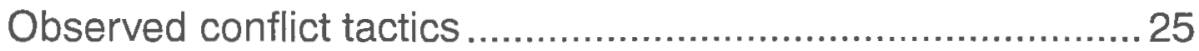

Practiced conflict tactics.................................................. 26

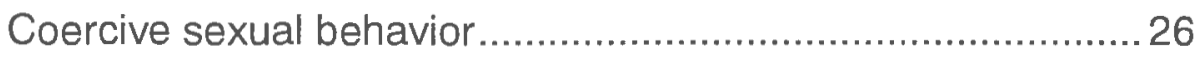

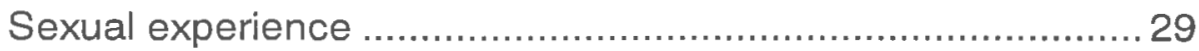

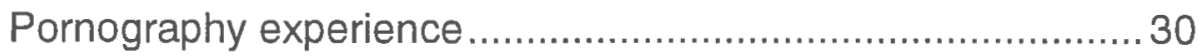




\section{TABLE OF CONTENTS (continued)}

Sexual arousal

Stimuli 33

Procedure 35

Introduction and survey completion 35

Physiological and subjective arousal measurement 35

Debriefing and closure

Data analysis 37

Design and power considerations. 37

Bivariate correlations 38

Quasi-experimental analyses. 39

Multiple Regression analyses

Results

Demographic characteristics and descriptives 40

Sexual orientation 40

Description of arousal to stimuli 40

Coercive sexual behavior 44

Prediction of Sexual Arousal to Erotic, Rape, and Non-sexual Violent Videos.

Regression analyses of predictors of sexual arousal to stimuli 44

Discriminant classification of high and low stimulus arousal .... 47

Comparisons of More Dichotomized Subsets of Those Aroused to Non-sexual Violence.

Comparisons of group means of most and least aroused 51 


\section{TABLE OF CONTENTS (continued)}

Correlations of individual difference measures

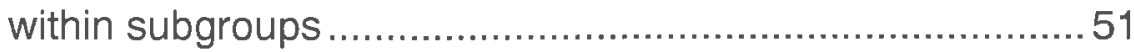

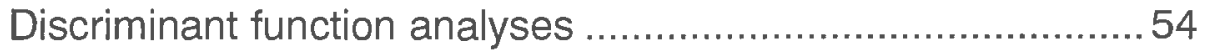

Correlational Analyses of Associations Among Individual Difference Measures ...............................................................5 57

Observed and practiced aggression and violence ..................5 57

Coercive sexual behavior and practiced aggression and violence .................................................................. 59

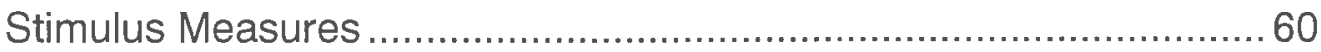

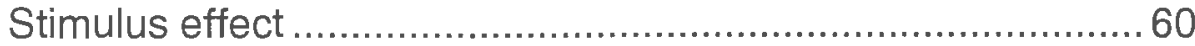

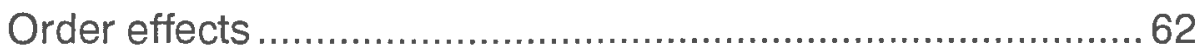

Individual differences and sexual arousal to rape and

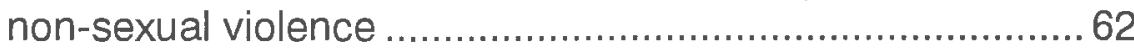

Physiological and subjective measures of arousal.................. 63

Sex experience and pornography use interaction and sexual arousal to rape and non-sexual violence

Discussion 66

Limitations of the Study ............................................................ 76

Implications for Future Research................................................ 80

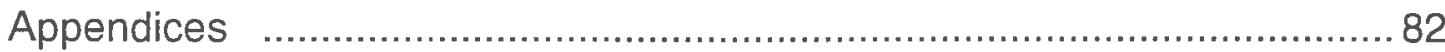

A: $\quad$ Recruitment Materials ...................................................... 82

B: $\quad$ Life Experiences \& Sexuality Survey .................................... 84

C: $\quad$ Consent Form for Research, I....................................... 91

D: $\quad$ Consent Form for Research, II........................................... 93 


\section{TABLE OF CONTENTS (continued)}

E: $\quad$ Exit / Debriefing Information................................................ 95

Bibliography 96 


\section{LIST OF TABLES}

Table 1 - Comparison of Non-participants vs. Participants

Table 2-Demographic Characteristics of the Complete Sample 42

Table 3 - Mean Measures by Maximum Arousal to Stimuli 45

Table 4 - Athletic Participation / Rape Tumescence Change Crosstabulation

Table 5 - Athletic Participation / Violent Tumescence Change

Crosstabulation.

Table 6 - Age / Violent Tumescence Change Crosstabulation 52

Table 7 - Comparison of Highest vs. Lowest Arousal to Violent Video. 53

Table 8 - Differences Between High Group and Low Group Correlations on Paired Associations .55

Table 9 - Correlations of Observed and Practiced Conflict Tactics .58

Table 10 - Tumescence / Lever Correlations 64 


\section{LIST OF FIGURES}

Figure 1 - Count of Participants Aroused to Stimuli at Percentage Ranges of Tumescence Increase Above Baseline.............................. 43

Figure 2 - Athletic Participation / Rape Tumescence ................................54

Figure 3 - Athletic Participation / Violent Tumescence ............................... 55

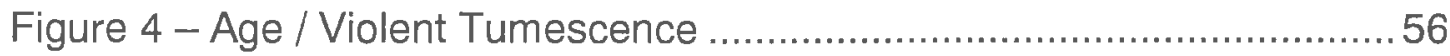

Figure 5 - Tumescence by Stimulus .................................................. 61

Figure 6 - Tumescence Percent by Stimulus...........................................61 
Observed Conflict, Sexual Experience, Pornography, and Coercive Behavior as

Predictors of Men's Sexual Arousal to Sexual and Violent Images

\section{INTRODUCTION}

In his essays on sexuality, Freud (1905/1962) offered a theoretical perspective that linked sexual and violent impulses, not as abnormal, but as typical human behavior with roots in our prehistoric past. Inadequate, primitive communication skills, he suggested, must have necessitated men's taking women by force to assure sexual access and reproduction. Projecting the lessons of the past onto his sophisticated contemporaries, Freud observed,

The sexuality of most male human beings contains an element of aggressiveness - a desire to subjugate; the biological significance of it seems to lie in the need for overcoming the resistance of the sexual object by means other than the process of wooing... The history of human civilization shows beyond any doubt that there is an intimate connection between cruelty and the sexual instinct...[pp. 23-25]

Taking a lesson from the animal world and even from our own history, with the ritualized fighting of medieval knights and the victors in wars, he who endures the battle reaps the rewards of his victory, often coming in the form of sexual access. Projected onto the present day, the message from much of the media is that men's efforts to impress women often takes the form of a ritualized aggression, whether it be "pumping iron" to impress her with a supernormal chest or behaving aggressively in a business endeavor. It seems almost inevitable that this value system would express itself in our intimate relationships. Thus Freud seems to have offered men a 'primal state' defense against charges of rape.

Epidemiological studies have presented a variety of incidence rates for 
attempted and completed rapes that quantify the effects of this so-called "primal state" behavior on American women. The incidence of sexual assault ranges from less than $8 \%$ (Riger \& Gordon, 1981; Winfield, George, Schwartz, \& Blazer, 1990) to Kilpatrick et al.'s (1985) $14.5 \%$ of 2,004 adult women in Charleston, South Carolina, through Russell's (1984) finding of $44 \%$ of a sample of 930 adult women in San Francisco. These prevalence rates raise even greater concerns when we focus on younger and more educated women (Koss, 1993, 1993a). In a national sample, Koss, Gidycz, \& Wisniewski (1987) found a $27.5 \%$ rate based on self-reports of 3,187 college women. Since then, cross-national figures on rape prevalence among college students point to a sobering consistency: completed and attempted rape over a lifetime has been reported universally by more than $20 \%$ of those responding (Koss, Heise, \& Russo, 1994).

Given these findings, the search for rapists through a narrow lens focused on a psychopathic fringe would seem to be inappropriate. Johnson's (1980) observation on the ubiquitousness of sexual violence seems perpetually apropos: "That sexual violence is so pervasive supports the view that the locus of violence against women rests squarely in the middle of what our culture defines as 'normal' interaction between men and women" (p. 146).

Support for the feminist contention that sexual aggression is a result of normal male socialization abounds, even across cultural lines (Hall \& Barongan, 1997; Rozee, 1993; White \& Sorenson, 1992). This especially rings true in a college-age population, where Muehlenhard and Linton (1987) found that $77.6 \%$ of women and $57.3 \%$ of men had been involved in some form of sexual 
aggression.

Is this coercive sexuality merely a toxic inheritance from our distant ancestors, or might it be a result of some more contemporary influence? According to social learning theory (Bandura, 1977; Bandura, Ross, \& Ross, 1963), most human behavior (including sexual violence) is learned through modeling and reinforcement. From observations of others we form ideas of how new behaviors are performed, storing these coded ideas as guides for future actions (O'Leary, 1988). A social-psychological approach to aggressive behavior focuses on features of the environment that foster the initial acquisition of the behavior, the environmental influences that facilitate the performance of aggressive acts, and conditions that maintain such behavior (Geen, 1990). Thus a young man observing his parents using physical violence in interpersonal conflicts (especially if the intent is to force the partner to engage in some activity), though not a necessary condition, is expected to increase the likelihood of his using the same tactics himself. In those instances where the goal is sexual access, a number of complex intervening variables, like physiological sexual arousal, affective motivation, cognitive distortions, and developmentally related personality problems (Hall \& Hirschman, 1991) could operate indirectly in influencing the practice of such modeled behavior.

If this young man observes parents or other influential persons in his family of origin using either verbally or physically aggressive tactics in dealing with conflict, does not see them punished for this behavior, and, in fact, sees them rewarded by others complying with their demands, this serves as a strong 
model for adopting similar tactics in his own personal resolution of conflicts. When this young man reaches puberty and begins dealing with the common tensions and conflicts related to negotiating for sexual access, such learned tactics may be expressed as coercive sexual behavior. During periods when his sexual activity and intimate interpersonal relations are minimal, he, like many others, may turn to pornography for stimulation, thus learning about coercive sexual behavior from the professionals. Then sex with some violence is probably most arousing. In fact, violence against women, in and of itself, may become arousing.

In spite of Freud's primal state curse, and in spite of the abundant acceptance in our culture of male dominance and even aggression against women, all men are not rapists, and all men are not sexually aroused by images of dominance and aggression. For those who are, is it possible to identify a set of common predictors of such behavior? Can we begin to isolate characteristics of men who are aroused to violence against women?

Within a non-incarcerated 'normal' population evidence of prior observation of parental violence, accompanied by both personal use of coercive tactics and frequent exposure to pornographic images (especially ones that reinforce the use of those tactics in a sexual context), might predict the successful merger of perceptions of violence with sexually arousing sensations. This association could manifest itself in both sexual arousal to violent images and the practice of coercive sexual behavior. It could also account for a person's "sociosexuality", differences in the willingness to engage in sexual relations 
without intimacy or commitment (Simpson \& Gangestad, 1991).

\section{Purpose}

This investigation was intended to analyze the relationship between observed parental conflict and one's own current conduct, in terms of both practiced non-sexual interpersonal conflict and coercive sexual behavior. Associations were explored among these behaviors and both sexual experience and the use of pornography. These variables were also examined for their ability to identify men most apt to be sexually aroused by images of sexual aggression and non-sexual violence. Other secondary, exploratory analyses investigated demographic correlates.

A self-report survey was administered to a sample of heterosexual undergraduate men measuring observed parental conflict, practiced non-sexual interpersonal conflict, coercive sexual behavior, sexual experience, pornography use, and demographic status. Then in a laboratory setting, subjective and physiological sexual arousal responses were monitored while a sample of men was presented with videotaped erotic, rape, and non-sexually violent stimuli.

The remainder of this chapter will critically survey current literature concerning the effects of witnessing parental aggression and violence, the sexual dynamics of aggressive behavior, sexual experience and aggression, psychophysiological reactions and sex experience, pornography and aggressive behavior, and the physiological measurement of sexual arousal. Specific hypotheses suggested by this review were tested in this investigation. 


\section{Witnessing Parental Aggression and Violence}

For decades, research has highlighted the frequency and severity of domestic violence both in the United States (Straus \& Gelles, 1990; Straus, Gelles, \& Steinmetz, 1980) and in the United Kingdom (Russell \& Hulson, 1992; Carrado, George, Loxam, Jones, \& Templar, 1996) at the same time that it has acknowledged the very high probability that children will witness this violence within their family of origin (Carlson, 1984). Somewhere between $9 \%$ and $27 \%$ of adults report having witnessed physical conflict between their parents during their childhood (DeMaris, 1992; Henning, Leitenberg, Coffey, Turner, \& Bennett, 1996; Kalmuss, 1984).

A recent review of 29 different studies of the effects of witnessing domestic violence on children's functioning indicates that such children are at risk for problems in behavioral, emotional, social, cognitive, and/or physical domains of functioning (Kolbo, Blakely, \& Engleman, 1996). Examples of negative effects include conduct disorders in boys and inadequacy-immaturity in both boys and girls (Jouriles, Murphy, \& O'Leary, 1989), special schooling, and various physical ailments (Stagg, Wills, \& Howell, 1989). The impact on a child witnessing overt violence between adults is complex and interacts with other aspects of family aggression, like watching parents throw things (Jouriles, Norwood, McDonald, Vincent, \& Mahoney, 1996), and hearing parents verbalize threats to leave the household (Laumakis, Margolin, \& John, 1998), actions that can amplify the severity of the effects (Cummings, 1998). Hostile family conflict has been linked to children's later difficulty in establishing autonomy and relatedness in 
interactions with parents (Allen, D'Alessio, Emmers, \& Gebhardt, 1996).

Both family tension and parental disharmony have been highlighted for their aggression-generating effects on children (McCord, 1986). In fact, even witnessing angry exchanges between adults whom they don't know can stimulate young children to hit, kick, and push each other (Cummings, lannotti, \& ZahnWaxler, 1985) or display other overt behavioral distress (El-Sheikh \& Reiter, 1996). However, it is those adults who are most powerful in children's lives, dispensing both rewards and punishments, who are especially likely to be copied by children who are dependent upon them (Bandura, Ross, \& Ross, 1963). According to Bandura (1977), individuals engage in modeled behavior if they attend to the modeled event, encode the event in memory, are capable of performing at least an approximation of what they observe, and, probably most important, if they determine that their own performance of that behavior will provide some positive consequences or gain. Bandura's analyses of observational learning generally demonstrate that children quite often learn behavioral expectations in any given situation by observing what others do. When children see adults fight without negative consequences, they learn that they too can solve their problems by attacking people.

Even though it may not be a universal characteristic of all boys who grow up in such an environment, overt fighting between mother and father certainly must be regarded as a significant risk factor that increases the likelihood that those boys will become aggressive men (Berkowitz, 1993). It may well be that by watching so much aggression they become desensitized and indifferent to violent 
behavior and their inhibitions against aggression weaken, since they perceive that attacking others to further their own interests is effective and not punished.

The prevalence of family abusers who were abused themselves while growing up is reported so frequently in research that terms like 'the cycle of violence' and 'the intergenerational transmission of aggression' have become conventional sociological and psychological concepts (Berkowitz, 1993).

Evidence of the normative approval of violence and its effect on youthful observers abounds. A study carried out for the National Commission on the Causes and Prevention of Violence (Owens \& Straus, 1975) found that those who had observed more frequent violence as youths tended to resort more often to violence in their interactions as adults, approving of spanking disobedient children and believing it to be acceptable for a husband to slap his wife if they have an argument or if she insults him. According to the 1975 National Family Violence Survey (Straus, Gelles, \& Steinmetz, 1980), men who had watched their parents fight when they were children were $2 \frac{1}{2}$ times more likely to be abusive husbands than those who hadn't witnessed parental aggression, and, in fact, the more frequently these men had been physically punished as children, the greater was the probability that they would severely assault their spouses (Straus, 1983). Hotaling and Sugarman (1986) examined fifty-two studies in which battering husbands were compared to a matched group of nonabusive husbands to determine how they differed. More abusive husbands than nonabusive husbands were violent to their children (in 100 percent of the studies that looked at this variable), had witnessed violence in the family while growing up (in 88 
percent of the studies that investigated this factor), and had experienced violence while growing up (in 69 percent of the studies that made this comparison).

Henning, Leitenberg, Coffey, Bennett, and Jankowski (1997) found that when additional risk factors were controlled for, witnessing physical aggression in childhood continued to predict psychological difficulties in adulthood. Their conclusion confirmed prior studies with adults (Forsstrom-Cohen \& Rosenbaum, 1985) and children (Fantuzzo, DePaola, Lambert, Martino, Anderson, \& Sutton, 1991; Spaccarelli, Sandler, \& Roosa, 1994). Case descriptions of children have overwhelmingly pointed to a common conclusion, namely that open marital conflict is a fundamental ingredient of childhood problems in discordant families (Fantuzzo \& Lindquist, 1989). However, as boys develop through puberty, childhood problems take on a new dimension, triggered by the flow of new hormones. To date, little attention has been paid to the possible effect that observing parental violence has on influencing the practice of sexually coercive behavior.

\section{Sexual Dynamics of Aggressive Behavior}

Physiological arousal has been suggested as an important component in aggressive behavior. Schachter's (1964) two-factor theory of emotion and his research on the misattribution of arousal contribute to our understanding of how individuals interpret various heightened states of arousal. He described arousal as being diffuse and undifferentiated, making interpretation of specific emotional states arbitrary and easily manipulated, depending on situational cues. The 
interpretation, not the arousal itself, influences behavior. Thus, to label an emotion one needs both physiological arousal and social cues. In the absence of explained arousal, individuals use social cues to label the emotion that they are experiencing (Schachter \& Singer, 1962). This labeling process implies that ultimately our emotions are learned through the socialization process (Tedeschi \& Felson, 1994). If arousal is identified in terms of situational cues, then, as Nisbett and Schachter (1966) found, individuals may be encouraged to relabel their emotions when cues are manipulated.

To explain the conditions under which levels of arousal to a primary stimulus might be altered by a secondary stimulus, occurring either concurrent or subsequent to the primary one, Zillmann (1979) proposed a theory of excitation transfer. Residual excitation from one emotional reaction was said to intensify a subsequent or concurrent secondary state. Excitation transfer may intensify either sexual or aggressive behavior and experience in situations that involve both sexual and aggressive stimulation and action. Sex-aggression fusion, in fact, is more likely to occur when brief episodes of aggression are interspersed in sexual activities (Zillman, 1984). If a primary reaction is one of annoyance, anger, or rage, the arousal accompanying sexual cues will fuel those responses. If the reaction is sexual excitement, arousal from conflict, annoyance, provocation, or pain will intensify sexual behavior and experience.

Research with both men and women has suggested that under certain conditions anxiety may facilitate sexual arousal. Dutton and Aron (1974) found higher levels of sexual arousal following anxiety evoked by fear of crossing a 
suspension bridge. Hoon, Wincze, and Hoon (1977) found that women became more sexually aroused and became aroused more rapidly after being distressed by an anxiety-producing film than following a neutral affective stimulus. A study by Wolchik, Beggs, Wincze, Sakheim, Barlow, and Mavissakalian (1980), seeking to extend the findings of Hoon, Wincze, and Hoon to men, found that such facilitation depends on the type and intensity of the distressing experience. Order effects were noted such that the most distressing film, one of limb amputation, probably evoking the strongest excitation, resulted in greater tumescence than pre-exposure to a control film. However, preexposure to a tragic automobile accident film produced less tumescence than the control film. Barlow, Sakheim, and Beck (1983) divided men into three groups in which they viewed an erotic film in conjunction with the threat of shock, with the threat of shock if they did not achieve an erection of a certain size, or with no threat of shock. Greater increases in penile circumference were shown under the contingent-shock condition, followed by the noncontingent-shock condition, with the least arousal being produced by the no-shock threat. Similarly, in another study (Heiman \& Rowland, 1983), a group of sexually functional men became more physiologically aroused to erotic audio tapes following a set of instructions designed to induce high performance demand than did a group following low performance demand, sensate focus instructions. In a study which examined the relationship between sexual arousal and guilt, Morokoff (1985) found that women who were higher in sex guilt showed greater vaginal vasocongestion in response to an erotic videotape than women low in sex guilt. 
Anxiety pre-exposure to a video depicting threatened amputation relative to pre-exposure to a neutral videotape has been found to enhance both the rate and magnitude of genital arousal in women (Palace \& Gorzalka, 1990). In another study (Franklin, Morokoff, \& Calderone, 1991) order effects in stimuli presentation were found, though contrary to expectations. When the erotic stimulus was presented first there was no residual enhancement of sexual arousal to stimuli that followed. However, when the first stimulus presented was non-sexual violence, there did appear to be a priming effect or an enhancement of sexual arousal to stimuli that followed (P. J. Morokoff, personal communication, November 21, 1996).

Collectively, these findings support Zillman's theory that residual arousal not identified with a particular emotion may facilitate sexual responses. Since quarreling and fighting, being threatened, fear, and being beaten (characteristics of a discordant family) all involve increased arousal, they may potentially intensify subsequent sexual excitation when such cues are again present (Zillmann, 1984).

\section{Sexual Experience and Aggression}

Assessing the variety of an individual's sexual experience may be useful in the prediction of sexual aggression due to factors of opportunity or access. Indeed, Malamuth (1986) did find sex experience to be a significant predictor of self-report sexually coercive behavior where more experience was associated with more sexually coercive behavior, but he found no significant overall association between sexual experience and either a tumescence index of sexual 
arousal (measured while reading stories depicting rape and mutually consenting sex), an index of self-reported arousal, or acceptance of self-reported non-sexual interpersonal violence against women.

Other studies of college men who engaged in some degree of sexual aggression (Kanin, 1957, 1983) found that the more sexually aggressive an individual was, the more likely he was to view sexuality as a means of establishing self-worth, and as an arena for 'conquest'. The men in this category reported more sexual experience at an earlier age, but, at the same time, were less likely to view these experiences as satisfactory. Studies of convicted rapists reported by Langevin, Paitich, and Russon (1985) reported similar findings. In a survey of 796 college students concerning sexual attitudes, experiences, and knowledge, Fischer (1992) found that greater sexual experience was evident in 73 percent of forcible and 71 percent of verbally coercive sexual behavior by men.

\section{Psychophysiological Reactions and Sex Experience}

In spite of the plausibility that women having greater past sexual experience would be more easily aroused by erotic stimuli in the laboratory, Morokoff $(1981,1985)$ found, to the contrary, that exposure to explicit erotica is more facilitative of physiological sexual arousal for the woman with less experience than for those with more. Similar patterns in sex guilt and sexual arousability prompted her to characterize all three aspects as sexual inhibition. Thus, she speculated that women who have guilt about sex, perceive themselves as low in arousability, and have less sexual experience are more inhibited and 
have greater physiological response during erotic stimulus presentation but report feeling less aroused when compared to uninhibited women. In a study of undergraduate males' reactions to sexual and violent videotapes, Franklin, Morokoff, and Calderone (1991) found an inverse relationship between sex experience and physiological sexual arousal to a non-sexual, purely violent stimulus.

In a study of men's sexual arousal to rape depictions, Malamuth and Check (1983) reported that arousal to these stimuli were inversely related to the participant's sexual experience. They interpreted these findings as being supportive of theories suggesting that a lack of somatosensory pleasurable experiences contribute to the development of sexually aggressive tendencies, or that the association between sexual experience and arousal to rape may, in fact, be due to some third variable, like hostility toward women. Investigating individual differences in effects on rape myth acceptance as a result of viewing aggressive pornography, Malamuth and Check (1985) found that less sexual experience contributed to the participant's evaluation of a rape victim's experience as being ultimately a positive one.

In terms of a topology of sexual aggression, Koss, Leonard, Beezley, \& Oros (1985) classified men into four groups (sexually assaultive, sexually abusive, sexually coercive, or sexually non-aggressive) according to their responses to the Sexual Experiences Survey (Koss \& Oros, 1982) and found that the number of sexual partners was a discriminating variable. Those men with a higher number of partners were more likely to report sexual coercion or assault, 
while those with fewer partners reported non-aggressive sexual behavior. More recently, Christopher, Madura, and Weaver (1998) used these measures to identify men's greater acceptance of rape myths and higher frequency of relationship conflict.

\section{Pornography's Effect on Aggressive Behavior}

Social cognitive learning theory (Bandura, 1977) specifies the mechanisms by which individuals may be influenced by the environment to which they are exposed and the conditions under which some influences are more likely to occur. There is no broad-based consensus among researchers about the mechanisms involved when exposure to pornography influences sexual arousal and aggression due to disparate theoretical orientations and ambiguous findings. Nonetheless, Malamuth's (1994) conclusions do seem to summarize some areas of agreement among researchers. First, it would seem that continued exposure to some media presentations may affect people's attitudes and perceptions, even when they are aware that those depictions are fictitious. And, secondly, exposure to fictionalized media portrayals of sexually violent messages may affect people's attitudes. It is not surprising that rapists have reported an earlier age of 'peak experience' with pornography and have been found to be more likely than other men to have encountered pornographic photos displaying explicit sexual acts (rather than nudes) at an earlier age and to have had a greater desire to imitate the activity portrayed in pornography.

Since rapists are more likely than other men to have come from home environments where education about sexuality was restricted and sex was a 
taboo subject, it would be expected that exposure to pornography would exert a more powerful influence, because it would become a primary source of information about sexuality (Goldstein, Kant, \& Hartmann, 1973).

Investigating sexual violence in the media, Malamuth and Briere (1986) proposed that cultural environmental factors (including mass media pornography) and individual variables interact to affect some people's thought patterns and other responses that may lead to antisocial behavior, including aggression. In yet another study, Malamuth and Check (1985) found that belief in the sexual violence myth (that women enjoy being raped and forced to have sex) was associated with frequency of exposure to pornography. Analysis of media effects by Berkowitz (1986) produced a somewhat qualified conclusion, i.e., that mass media exposure produced only short-lived effects because its influence stems largely from the temporary activation of ideas that may intensify the viewer's existing behavioral tendencies. Such short-lived effects were confirmed by Malamuth and Ceniti (1986). Meanwhile, in a complex analysis of habituation from repeated exposure to sexually violent or nonviolent stimuli, Ceniti and Malamuth (1984) suggested that conditioning and other learning mechanisms might mediate the effects of exposure to erotica. They also proposed that some stimulus parameters like intensity and interstimulus interval may affect habituation responses. Specifically, they suggested that an intensity effect was demonstrated as well as an interstimulus interval effect that was inversely related to the rate of habituation. 
Probably the most comprehensive model of the interaction among response components in sexual arousal is that proposed by Byrne (1986). For Byrne, the sexual behavior sequence is multidetermined and comprised of a number of reciprocally influencing processes describing external events (erotic stimuli and partner behaviors), internal mediational variables, and the more enduring cognitive-affective reactions (the range of behavioral outcomes). A major contribution of this model is its delineation of a generalized evaluativeemotional response array with a positive (erotophilia) or negative (erotophobia) valence. Regrettably, however, Byrne's model is highly complex, with an elaborate network of feedback loops, making clear predictions difficult if not impossible (Rosen \& Beck, 1988).

Barlow's (1986) model, though it focuses primarily on aspects of sexual dysfunction, postulates a sequence of interactive processes as well. The process begins with some perceived expectation for sexual arousal, followed by either a positive or negative emotional response. This response, in turn, influences the features of the erotic situation that focus further attention as well as triggering autonomic arousal, directing attentional focus.

More recently, Hall and Hirschman (1991) have integrated elements of existing models into a comprehensive model in which the probability of sexually violent behavior is a function of the relative prominence of motivational precursors (physiological sexual arousal, cognitions that justify sexual aggression, affective dyscontrol, and personality problems). Here sexual arousal is seen as a physiological impulse that results in sexual behavior that becomes 
inappropriate only when expressed inappropriately. Given that similar physiological processes underlie sexual arousal that results in appropriate sexual behavior as well as that which results in sexual violence, it follows that physiological sexual arousal must be cognitively appraised before it is acted on.

If sexually violent behavior toward women is not appraised as being wrong, then there is no moral or ethical reason to control such behavior. Thus, physiological sexual arousal may be fused with a cognitive appraisal factor facilitating sexually violent behavior. Negative affective states of anger and hostility, normally inhibited in the expression of appropriate sexual behavior, may become so powerful and compelling that they overcome those inhibitions and result in the expression of sexually violent behavior. Or, in some cases, enduring personality problems may interact with physiological sexual arousal, sexually aggressive cognitions, or affective dyscontrol, promoting severe and chronic sexually violent behavior in a man not otherwise identified as sexually violent.

\section{Physiological and Subjective Measures of Sexual Arousal}

In a study of prisoners who volunteered for assessment, tumescence in response to erotic slides has been shown to be reliable over a two week period (Wormith, 1986). Test-retest reliability ranged from 0.53 to 0.92 for tumescence in response to erotic slides. An investigation of test-retest data for raw change scores resulted in correlation coefficients for tumescence data that ranged across the slide set categories from 0.50 to 0.83 . Similarly, Day, Miner, Sturgeon, and Murphy (1989) assessed five different composite scores of sexual arousal to a variety of stimuli across numerous modalities and reported Cronbach's coefficient 
alpha scores of $0.89,0.95,0.87,0.86$, and 0.91 . Even with such reliability measures, however, a basic problem with these gauges is that they are not necessarily linear across the full range of flexion. Due to potential scaling problems with the gauges, stimulus materials, and the penile response itself, researchers (Earls \& Marshall, 1983; Farrall \& Card, 1988) have recommended use of a comparative form of scaling, using the individual's own response as the control.

Wormith (1986) reported internal consistency correlations ranging from 0.42 to 0.90 for self-report scores of subjective sexual arousal, and test-retest data for raw change scores that yielded correlation coefficients for self-report data ranging from 0.65 to 0.86 .

\section{Correlates of Sexual Aggression}

Sexual aggression is a complex construct that is multiply determined and shaped by societal and institutional support, the context of interpersonal relations, and unique individual characteristics. In a college-age population it is inevitable that the search for correlates focus on fraternities and athletic teams. Koss and Gaines (1993) emphasize this empirical focus due to the nature of fraternities, often characterized as environments where antisocial behavior is condoned, such as excessive drinking and abuse of women, and athletic teams, where an aura of elitism and invulnerability is fostered, as well as reinforcing, often glorifying, the physical domination of others. In their sample they found some predictive importance in athletic participation, but less in fraternity affiliation, except indirectly through alcohol use. 
Lackie and de Man (1997) found a significant, moderate correlation between sexual aggression and fraternity affiliation, but not with athletic involvement. Regression analysis also identified fraternity affiliation, along with physical aggression and sex role stereotyping, as the most important predictors of sexual aggression. Other findings (Ray \& Gold, 1996), however, suggest that this association may be more complex, since fraternities tend to be arenas of exaggerated gender roles and elevated consumption of alcohol, and this interaction may be more indirectly involved in sexual aggression.

\section{Summary and Study Hypotheses}

The present study explored the influence of both historical (observed conflict, sexual experience, and pornographic experience) and current (coercive behavior) variables on physiological sexual arousal in a sample of heterosexual undergraduate men.

Parental conflict observed by the participant, the participant's own level of conflict in interpersonal relations, practiced coercive sexual behavior, the variety of sexual experience, and the frequency and class of pornography used were assessed as possible predictors of the amplitude of both physiological and subjective sexual arousal to various video taped stimuli. Relationships within the set of predictors were also investigated. It was predicted that:

1. The reported frequency of observed family conflict in the categories of verbal aggression and physical aggression will be positively correlated with the frequency of self-reported personal conflict tactics practiced in interpersonal relations. 
2. Groups based on the severity of self-reported sexually coercive behavior will report frequencies of personal conflict tactics, in the categories of verbal aggression and physical aggression, that differ significantly from each other. The greater the severity level of the group, the greater the frequency of self-reported conflict tactics.

3. Participants who report higher levels of observed parental conflict, in the categories of verbal aggression and physical aggression, will show significantly more physiological sexual arousal to stimuli depicting either rape or non-sexual violence, measured by percentage of increase in maximum penile tumescence over baseline tumescence, than those who report having observed little or no such conflict.

4. Participants who report higher levels of the frequency of selfreported personal conflict tactics practiced in interpersonal relations in the categories of verbal aggression and physical aggression will show significantly higher physiological sexual arousal to stimuli depicting either rape or non-sexual violence, measured by percentage of increase in maximum penile tumescence over baseline tumescence, than those who report lower levels.

5. Groups based on the severity of self-reported sexually coercive behavior will show levels of physiological sexual arousal to stimuli depicting either rape or non-sexual violence, measured by percentage of increase in maximum penile tumescence over baseline tumescence, that differ significantly from each other. The greater the severity level of the 
group, the greater the level of arousal.

6. There will be an effect for order; that is, presentation of the nonsexual violent stimulus first will result in greater measured arousal to the stimuli that follow.

7. There will be an effect for stimulus; that is, change in percentage of increase in maximum penile tumescence over baseline in response to erotic, rape, and non-sexual violent stimuli will each be significantly greater than to the neutral stimulus.

8. The measurement of maximum lever placement, representing selfreported subjective sexual arousal experienced during stimulus presentations, will correlate positively with the respective physiological measure of tumescence change for each of the experimental stimuli.

9. Individuals with both low sexual experience and high pornography exposure will show higher physiological sexual arousal to stimuli depicting either rape or non-sexual violence, measured by percentage of increase in maximum penile tumescence over baseline tumescence, than those with high sexual experience and high or low pornography exposure, as well as those with both low sexual experience and low pornography exposure.

10. A set of predictors (observed parental conflict tactics, practiced conflict tactics, and coercive sexual behavior) will account for a significant proportion of variance in maximum measured penile tumescence. 
METHOD

\section{Participants}

Study participants were undergraduate men recruited from psychology, sociology, ROTC, as well as nursing classes, athletic teams, and fraternities. Flyers were distributed, and a notice was posted in the Psychology Department requesting volunteers to sign up for individual sessions (see Appendix A). Ninety-four men volunteered for the study, and informed consent was obtained. Course credit or community service credit was offered as compensation for participation. Data from four participants were discarded due to equipment malfunction, and eight declined participation in the second portion of the study and were excused. Data from the remaining eighty-two participants, those who completed both parts of the study, were included in the data set for further analysis.

At all times care was taken to insure that participants were treated in accordance with guidelines of the Code of Federal Regulations (45 CFR 46, revised June 1991), "Ethical Principles of Psychologists and Code of Conduct" (American Psychological Association, 1992), and "Ethical Principles in the Conduct of Research with Human Participants" (American Psychological Association, 1982).

\section{Measures}

Demographic data and relevant activities.

Demographic data were collected, and a number of relevant activities were measured. Participants were asked to report their age, sexual orientation, 
current length of intimate relationship, frequency of sexual intercourse, number of sexual partners since becoming sexually active, fraternity affiliation, and athletic involvement.

Sexual orientation (Appendix B, item 2) was rated on a five-point scale representing the following range: 'exclusively heterosexual', 'mostly heterosexual', 'bisexual', 'mostly homosexual', and 'exclusively homosexual'. This measure was used to screen participants, since all stimuli reflected a heterosexual orientation. Intimate relationship (item 3) had response options of 'less than one month', 'from one to six months', 'from six months to a year', 'more than a year', and 'never had an intimate relationship'; sexual intercourse (item 4) had response options of 'never', 'occasionally', 'once a month', 'weekly', and 'at least once daily'; and sexual partners (item 5) had response options of 'none', 'one', 'two to four', 'five to nine', and 'ten or more'.

Fraternity affiliation (item 6) had response options of 'never rushed, pledged, or belonged', 'rushed/not pledged', 'pledged/not active', and 'active member', and athletic involvement (item 7) had response options of 'do not participate at any level', 'participate informally, no regular team play', 'participate in club sports', 'participate in varsity sports, not basketball or football', and 'participate in varsity basketball or football'.

Parental status (item 10) had response options of 'married \& living together', 'separated', 'divorced', 'widowed', or 'other', and living arrangement (item 11) had response options of 'mother \& father', 'mother only', 'father only', 'mother \& partner', 'father \& partner', and 'other'. 
Observed conflict tactics.

Modified versions of The Conflict Tactics Scales (Straus, 1979) were used to measure parental aggression and violence observed in the family of origin (see Appendix B). These scales were developed at the University of New Hampshire in the 1970 s and have been frequently adapted for use in a variety of research settings. In the scales the range of conflict responses are presented hierarchically, measuring three categories of tactics, namely reasoning, verbal aggression, and physical aggression. In prior studies, where the focus was on husband to wife conflict, the three scales demonstrated coefficients of reliability of $.50, .80$, and .83 , respectively (wife to husband coefficients were $.51, .79$, and .83 , respectively) (Straus \& Gelles, 1990).

For this study the scales assessing frequency of tactic use were slightly modified from their usual seven forced-choice categories (i.e., 1 X, 2X, 3-5X, 610X, 11-20X, more than 20X, and never) to be more consistent with other responses on the survey. In this case responses ranged over a 5-point scale (never, rarely, sometimes, frequently, and always). Instructions were modified to ascertain how often the participant observed one or both parents utilizing a range of tactics in dealing with interpersonal conflict:

No matter how well a couple gets along, there are times when they disagree, get annoyed with the other person, or just have spats or fights because they're in a bad mood or tired or for some other reason. They also use many different ways of trying to settle their differences.

The list below contains some things that your parents or your mother or father or other caretaker and the person they lived with or dated most often might have done when they had an argument. When they had an argument, how often did one or the other or both... 
Scores were summed in the categories of aggression and violence to produce three subscales of interest to this research. Observed verbal aggression (items 15 through 19, with scores ranging from 5 through 25) included items such as 'insult or swear at the other'. The category of observed physical aggression was further divided into observed minor violence (items 20 through 24; e.g., 'throw something at the other', with scores ranging from 5 through 25) and observed severe violence (items 25 through 30; e.g., 'kick, bite, or hit the other with a fist', with scores ranging from 6 through 30 ). The three subscales were then summed to produce a measure of the total aggression and violence observed between parents in the family of origin, with scores ranging from 16 through 80.

\section{Practiced conflict tactics.}

The Conflict Tactics Scales were then repeated with slightly modified instructions in order to ascertain the frequency and degree of conflict tactics practiced by the participant in his current intimate relationships:

In your own current intimate relationship (or last previous one), no matter how well you get along as a couple, there are times when you may disagree, get annoyed with your partner, or just have spats or fights because you're in a bad mood or tired or for some other reason. You also use many different ways of trying to settle your differences.

The list below contains some things that you, yourself might have done when they had an argument. During this past year, when you had an argument with your partner (or if you had no relationship in the past year, try to imagine how you would have acted), how often did you, yourself...

Like the observed conflict tactics noted above, scores were again

summed in the categories of aggression and violence to produce three additional 
subscales of interest to this research, practiced verbal aggression (items 34 through 38 , with scores ranging from 5 through 25), practiced minor violence (items 39 through 43, with scores ranging from 5 through 25), and practiced severe violence (items 44 through 49, with scores ranging from 6 through 30 ). These three subscales were also summed to produce a measure of the total non-sexual aggression and violence practiced by the participant in his interpersonal relationships, with scores ranging from 16 through 80 .

$\underline{\text { Coercive sexual behavior. }}$

A 10-item self-report instrument, the Sexual Experiences Survey (Koss \& Gidycz, 1985; Koss, Gidycz, \& Wisniewski, 1987; Koss \& Oros, 1982) was incorporated into the survey (Appendix B, items 50 through 59) in order to identify the extent of coercive sexual behavior that the participant practices in his current intimate relationships.

The Sexual Experiences Survey internal consistency (Cronbach alpha) has been calculated at .89 for men, and test-retest reliability rate, determined by comparing scores a week apart, was determined to have a mean item agreement of $93 \%$ (Koss \& Gidycz, 1985). Validation through follow-up personal interview yielded a Pearson correlation of .61(p<.001), signifying the degree of relationship between self-report level of aggression and that given in the presence of an interviewer (Koss \& Gidycz, 1985). A further validity study indicated that $93 \%$ of the participants gave the same responses to Sexual Experiences Survey items on self-report and in interviews (Koss, Gidycz, \& Wisniewski, 1987). 
Participants were classified on the basis of the most severe self-reported coercive sexual behavior according to categories developed by Koss and associates (Koss, Gidycz, \& Wisniewski, 1987). Those who did not admit to engaging in any coercive, abusive, or assaultive sexual behavior toward women ('No' responses on items 50 through 59, inclusively) were considered "sexually non-aggressive". Those who admitted sexual behavior that did not involve attempted penetration subsequent to verbal pressure, misuse of authority, threats of harm, or actual physical force ('Yes' responses to items 50, 51, or 52, but not to any higher numbered items, e.g., 'Has a woman given in to sex play with you (fondling, kissing, or petting, but not intercourse) when she didn't want to because she was overwhelmed by your continual arguments and pressure?') were considered having "sexual contact". Men who report either having obtained sexual contact by the use of threats of force or actual force or administering any drug or intoxicant for that purpose or those who unsuccessfully attempted intercourse using these same tactics ('Yes' responses to items 53 or 54, but not to any higher numbered items, e.g., 'Have you ever attempted sexual intercourse with a woman (get on top of her, attempt to insert your penis) when she didn't want to because you threatened or used some degree of physical force (twisting her arm, holding her down, etc.) to make her?')) were classified as having "attempted rape". Those who admitted engaging in sexual intercourse subsequent to the use of menacing verbal pressure or the misuse of authority ('Yes' responses to items 55 or 56 but not to any higher numbered items, e.g., 'Has a woman given in to sexual intercourse with you when she didn't want to 
because she was overwhelmed by your continual arguments and pressure?') were considered as having used "sexual coercion". And, finally, men who said they had engaged in vaginal, oral, or anal intercourse, either by the threat of force, by the actual use of physical force, or by administering any drug or intoxicant for that purpose ('Yes' responses to items 57, 58, or 59, e.g., 'Has a woman had sexual intercourse with you when she didn't want to because you threatened or used some degree of physical force (twisting her arm, holding her down, etc.) to make her?'), were characterized as having perpetrated "rape".

\section{Sexual experience.}

The diversity of an individual's sexual experience was surveyed using The Cowart-Pollack Scale of Sexual Experience (Cowart-Steckler \& Pollack, 1988), a 30-item self-report Guttman-scaled instrument derived from previous scales (Bentler, 1968a, 1968b; Zuckerman, 1973) and normed on a college population, yielding coefficients of reproducibility of .88 (Cowart \& Pollack, 1979) and .87 (Cowart-Steckler, 1984). Responses on this scale (Appendix B, items 60 through 89) were summed to provide an overall measure of the participant's variety of sexual experience.

Two separate, single-item measures, frequency of sexual intercourse (item 4, with response options of 'never', 'occasionally', 'once a month', 'weekly', and 'at least once daily' and scores ranging from 1 to 5) and number of sexual partners (item 5, with response options of 'none', 'one', 'two to four', 'five to nine', and 'ten or more' and scores ranging from 1 to 5), provide measures of alternative aspects of sexual experience. 
Pornography experience.

The extent of the participant's exposure to, and use of, sexually explicit or pornographic materials (e.g., books, magazines, films, videotapes) was assessed through responses to questions of frequency of use of such materials (Demaré, Briere, \& Lips, 1988) depicting three subscales of acts embedded in a list including five distracter items (e.g., 'Sexual acts with animals'). The rating scale of frequency for each item ranged from 'never' through 'occasionally', 'once a month', 'weekly', and 'daily'.

Scores for the three subscales were used to determine the frequency of use of different types of pornography and sexually explicit materials.

Participants' responses that represented the higher frequency of viewing two acts (Appendix B, item 93, 'a man forcing a woman to perform a sexual act against her will' or item 95, 'rape of a woman (or women) by a man (or many men)') were coded as sexually violent pornography frequency. Responses that represented the highest frequency of viewing three acts (item 96, "bondage of women,' item 98 'torture or mutilation of women,' or item 92, 'whipping, spanking, or beating of women') were coded as non-sexual violent pornography frequency. And the participants' reported frequency of viewing the single act represented by item 100, 'mutually consenting sex between a man and a woman (not involving any of the above themes),' was coded as erotic pornography frequency. Scores for each subscale ranged from 1 to 5 . These three subscales were also summed to produce a measure of the total frequency of viewing erotic, sexually 
violent, and non-sexual violent pornography, with scores ranging from 3 through 15.

Sexual arousal.

In order to ascertain participants' physiological sexual arousal to a variety of potentially sexual stimuli, plethysmographic measurements were made of penile tumescence using a strain gauge and recorded on a polygraph calibrated to represent circumference change in the shaft of the penis. A Grass Model 7E polygraph was coupled through the wall of the experimental room. One channel was connected through a Grass Model 7MGAB Strain Gage Adapter to a capillary strain gauge (Rosen \& Beck, 1988), which operates such that during erection a silastic tube containing a column of mercury increases in length and decreases in diameter, increasing the resistance displayed on the polygraph. Thus, the resistance changes are in direct proportion to changes in the circumference of the penis (Geer, 1976). Prior to each measurement session the strain gage was calibrated against a graduated cylinder with known diameters, permitting the conversion of millimeters of deflection from baseline on polygraph tracings to an absolute scale of circumference change. After each use strain gages were washed with soap and water, soaked for 45 minutes in activated glutaraldehyde (Cidex 7), and then thoroughly rinsed, dried, and placed in a plastic bag before the next use. Prior to the stimulus presentation, a measure of baseline tumescence was determined. Then, maximum deflection from baseline was measured during the stimuli presentations, resulting in scores for maximum neutral tumescence, erotic tumescence, rape tumescence, and 
violent tumescence. Scores can range from 75 millimeters through 160 millimeters.

Self-reported subjective sexual arousal, experienced during stimulus presentation, was continuously monitored using the movements of a lever by the participant. A second channel of the polygraph was connected to a leveroperated potentiometer (Wincze, Hoon, \& Hoon, 1977). The apparatus consists of a potentiometer driven by a mechanical lever which swings approximately through a $180^{\circ}$ arc corresponding to a scale from 0 to $100 \%$ sexual arousal and is mounted on a table adjacent to the participant in such a manner that the lever can be operated comfortably with the right hand. The movement of the lever was demonstrated, and various points on the arc were identified as representing 'no arousal', 'about half aroused', 'more aroused', 'less aroused', and 'about as aroused as I can possibly be'. Participants were told to use the lever at all times to represent their perceived sexual arousal, even during the period between stimuli, the interstitial stimulus interval. Each person was given an opportunity to practice manipulating the lever through its minimum to maximum range. A sixvolt battery was connected across the potentiometer such that a voltage drop was produced proportional to the location of the lever in its range. The voltage differential drove a Grass 7-DAE driver amplifier, resulting in millimeters of pen deflection that correspond linearly to the position of the lever in its range. Prior to each measurement session the lever was calibrated through the range of minimum $(0 \%)$ to maximum (100\%) lever placement, permitting the conversion of millimeters of deflection from baseline on polygraph tracings to an absolute scale 
representing percentage of subjective sexual arousal. Maximum lever deflection from baseline was measured during the stimuli presentations, resulting in scores for maximum neutral lever, erotic lever, rape lever, and violent lever. Scores can range from $0 \%$ to $100 \%$.

\section{Stimuli}

Four videotaped vignettes, each of five minutes duration, separated from each other by a two-minute interstitial stimulus interval, served as the stimuli presented to each participant. Twelve undergraduate males, selected from a variety of different student organizations, volunteered to pilot test the stimuli and identify their perceptions of them on a short questionnaire using the characteristics 'sexually arousing', 'violent', 'both sexually arousing and violent', and 'neither sexually arousing nor violent'. Their responses unanimously confirmed the intended labeling of the stimuli.

One vignette, representing the neutral condition depicting no explicit sexual or aggressive behavior, was an excerpt from the film The Cruiser's Guide to the San Juan Islands, produced by Bennett Marine Video Presentations (Marina del Rey, CA). The film, an informative travel guide describing channel markers and waterway approaches to major harbors, is in color and has a natural soundtrack with a male narrator's voice. Pilot testing indicated that men find this sequence to contain neither explicit sexual nor violent scenes.

A vignette representing the condition of erotic arousal with explicit sexual behavior was an excerpt from the film Jamie Loves Jeff 2: Three Years Later, produced by Vivid Video (Van Nuys, CA). It is in color with a natural dialogue 
and soundtrack and depicts heterosexual petting, disrobing, cunnilingus, fellatio, and intercourse. Pilot testing indicated that men find this sequence sexually arousing but not violent.

Another stimulus, representing the condition of realistic rape arousal, demonstrating explicit sexual behavior as well as dominance and aggression with a realistically negative victim outcome, was an excerpt from the film The Reality of Rape, from Motorola Teleprograms, Inc. (New York), portraying both sexual behavior and violence. This color vignette, with natural dialogue and soundtrack, includes a man forcing a woman to perform fellatio and then forcing vaginal intercourse. Pilot testing indicated that this vignette is perceived as both sexual and violent, although the sexuality is masked by darkness and edited in a manner such that the sex acts are not explicitly shown.

Finally, a five-minute segment of film represented the condition of violent arousal with no explicit sexuality. It is from the film Extremities, produced by Paramount Home Video (Hollywood, CA), and was identified through pilot testing as being non-sexual but aggressive. This color vignette represents a dramatization of a man threatening and beating a woman. No sexually explicit scenes were included in this segment, and pilot testing found this segment to be perceived as violent.

All video stimuli were displayed on a Sony 20" Model KV2090R Video Monitor using a Panasonic Model AG1220 VHS 3-head Recorder/Player. 
Procedure

The experimental session lasted approximately one hour and was divided into two parts, each having its own separate consent form.

Introduction and survey completion.

Summarized information was presented about the study, and detailed specifics contained in the consent form were highlighted. Questions were answered, and the participant was invited to sign the informed consent form for the first part of the experiment (Appendix C), keeping one copy for his records. Upon signing the form, he was asked to complete the Life Experiences and Sexuality Survey, a comprehensive questionnaire of demographic data and activities, observed conflict tactics, practiced conflict tactics, coercive sexual behavior, sexual experience, and exposure to pornography (see Appendix B), requiring approximately $15-20$ minutes to complete. Surveys were then collected.

\section{Physiological and subjective arousal measurement.}

At the end of the first portion of the session, the participant was informed that his responses were part of a larger study involving physiological and subjective reactions to neutral, erotic, rape, and violent scenes on videotape. He was then invited to examine the experimental room, a private $2 \mathrm{~m}$. by $2.6 \mathrm{~m}$. room equipped with a reclining chair, video monitor, intercom, penile strain gauge, and a lever device for making subjective ratings. An adjoining control room contained all other equipment used. He was invited to sit in the reclining chair and was handed a clipboard containing two copies of the informed consent 
form for the second part of the experiment (see Appendix D). The sequence of the experiment was explained, including an examination of the strain gauge and an explanation of its placement halfway up the shaft of the penis. The operation of the lever-operated potentiometer was demonstrated, and the continuous values of perceived sexual arousal represented by points along its arc were explained. The participant was then given an opportunity to practice the lever. Questions and concerns were again solicited and addressed. At this point the participant was invited to sign the consent form, keeping one copy for his records, affirming his desire to continue with the experiment. All consent forms were stored separately from individual data without identifying participant numbers, ensuring confidentiality and anonymity.

After the consent form was signed, the experimenter then left the room, closed the door, and asked the participant to lock the door behind him so that he would be assured of privacy. The participant attached the strain gauge in private and informed the experimenter via intercom when the gauge was in place. Penile tumescence and subjective sexual arousal lever placement were measured continually throughout the remainder of the session. Recordings were made during a five-minute baseline period, followed by a five-minute period during which the neutral stimulus was presented. The neutral stimulus was followed by a two-minute interstitial stimulus interval where the video screen displayed a solid blue background and no audio. The participant then viewed one of the three videotaped segments, presented in one of six randomly assigned orders (Errotic, Rape, Violent; V,E,R; R,V,E; E,V,R; V,R,E; or R,E,V), 
each separated from the next by a two-minute interstitial stimulus interval as described above. Immediately upon completion of the last stimulus presentation, the participant was instructed via the intercom to remove the strain gage, fasten his clothing, unlock the door, and come out.

\section{Debriefing and closure.}

In order to maintain ethical conduct for research that includes exposure to images of rape and violence, the use of an educational briefing or debriefing has been shown to be effective in relieving any negative impact on the research participants (Allen, D'Alessio, Emmers, \& Gebhardt, 1996). Consequently, at the end of the session each participant was debriefed, the purpose of the study explained, and questions and concerns addressed. Educational materials were presented to the participant regarding rape myths, women's true responses to rape, and the negative consequences of battering (see Appendix E), since two of the stimuli presented depict dramatizations either of realistic rape or a brutal battering. Finally, the participant was thanked for his participation. Had any individual expressed distress as a result of the experiment, he would have been directed to one of the resources noted on his consent form. None did.

\section{Data Analysis}

\section{Design and power considerations.}

This study investigated bivariate correlations between the self-report measures of observed aggression and violence, practiced aggression and violence, and coercive sexual behavior, as well as physiological measures of penile tumescence and subjective lever measures representing perceived sexual 
arousal to video stimuli. Then a $2 \times 6$ mixed repeated measures factorial design was utilized. The first between subjects factor reflects a high/low grouping by median split on seven individual difference measures, observed parental verbal aggression, observed parental minor violence, observed parental severe violence, practiced verbal aggression, practiced minor violence, practiced severe violence, and coercive sexual behavior. The second between subjects factor is Order, representing the six possible orderings of the videotape stimuli. The set of dependent variables include the four different types of stimuli, neutral, erotic, rape, and violent. Finally, a multiple regression analysis explored predictors of physiological sexual arousal to both rape and violence.

Preliminary power analyses suggested that eighty-four participants would be required in order to allow adequate power (Cohen, 1988) to detect moderate (power $=.80$ ) effects. This number of participants would also allow adequate power for detection of bivariate correlation moderate effects.

\section{Bivariate correlations.}

Bivariate correlations were used to analyze the relationship between selfreport measures of observed parental verbal aggression, observed parental minor violence, observed parental severe violence, practiced practiced verbal aggression, practiced minor violence, practiced severe violence, as well as between physiological tumescence change and subjective lever position measures of sexual arousal. 
Quasi-experimental analyses.

In the quasi-experimental portion of the proposed study, five separate 2 (Group: High vs. Low ratings of observed parental aggression and violence, practiced aggression and violence, coercive sexual behavior, sex experience, and pornography use) $\times 6$ (Order: 1.- Erotic, Rape, Violent; 2.- V,E,R; 3.- R,V,E; 4.- $E, V, R ; 5 .-V, R, E ; 6 .-R, E, V)$ repeated measures factorial analyses of variance were performed. The dependent measure was tumescence increase over baseline to both rape and non-sexual violent stimuli. In order to avoid inflation of the alpha level, appropriate corrections were made by applying post hoc testing for simple effects.

Multiple regression analyses.

A multiple regression analyses explored observed parental aggression and violence, practiced aggression and violence, coercive sexual behavior, sex experience, and pornography use as factors that might predict physiological sexual arousal to rape and non-sexual violent videos in this sample. 


\section{RESULTS}

In order to determine whether the eight men who declined to participate differed from those who did participate, means for participants and nonparticipants were compared with independent samples tests for each of the demographic and individual difference measures. I tests revealed no significant differences between groups on any measure except for athletic participation $(\mathrm{t}(88)=2.64, \underline{\mathrm{p}}<.05)$. Men with greater formal athletic involvement were more likely to participate. Means and standard deviations are repeated in Table 1.

\section{Demographic Characteristics and Descriptives}

\section{Sexual orientation.}

The 82 participants who completed both parts of the study ranged in age from 18 to 33 years $(\underline{M}=19.41, \underline{S D}=2.17$ ). Three of the participants identified themselves as 'bisexual', one as 'mostly heterosexual', and the remaining 78 as 'exclusively heterosexual'. For the range of demographic characteristics of this sample see Table 2.

\section{Description of arousal to stimuli.}

Participants were classified sexually aroused by a video stimulus if tumescence increased at least $20 \%$ over baseline. By these criteria, 77 participants (94\%) were aroused to the erotic video, $36(44 \%)$ were aroused to the rape video, and $23(28 \%)$ were aroused to the non-sexual violent video. (see Figure 1). Figure 1 also indicates frequencies by stimulus of participants who were aroused $10-19 \%, 20-29 \%, 30-39 \%, 40-49 \%$, and over $50 \%$ above baseline. It was also of interest to examine the number of participants who exhibited 
Table 1 - Comparison of Non-participants vs. Participants

\begin{tabular}{|c|c|c|c|c|}
\hline & $\begin{array}{c}\text { Non- } \\
\text { Participants } \\
\text { Mean }\end{array}$ & $\begin{array}{c}\text { Std. } \\
\text { Deviation }\end{array}$ & $\begin{array}{l}\text { Participants } \\
\text { Mean }\end{array}$ & $\begin{array}{c}\text { Std. } \\
\text { Deviation }\end{array}$ \\
\hline Age & 20.50 & 2.93 & 19.41 & 2.170 \\
\hline $\begin{array}{l}\text { Intimate } \\
\text { relationships }\end{array}$ & 3.63 & 1.06 & 2.98 & 1.110 \\
\hline $\begin{array}{l}\text { Sexual } \\
\text { intercourse }\end{array}$ & 2.88 & 1.55 & 2.76 & 1.160 \\
\hline Sexual partners & 2.88 & 1.25 & 3.02 & 1.200 \\
\hline $\begin{array}{l}\text { Fraternity } \\
\text { affiliation * }\end{array}$ & 2.38 & 1.51 & 1.62 & 1.130 \\
\hline $\begin{array}{l}\text { Athletic } \\
\text { involvement }\end{array}$ & 1.75 & .71 & 2.74 & 1.040 \\
\hline $\begin{array}{l}\text { Observed verbal } \\
\text { aggression }\end{array}$ & 9.38 & 4.53 & 11.52 & 3.890 \\
\hline $\begin{array}{l}\text { Observed minor } \\
\text { violence }\end{array}$ & 6.38 & 2.26 & 6.77 & 3.540 \\
\hline $\begin{array}{l}\text { Observed } \\
\text { severe violence }\end{array}$ & 6.50 & 1.41 & 6.46 & 1.900 \\
\hline $\begin{array}{l}\text { Practiced verbal } \\
\text { aggression }\end{array}$ & 8.88 & 3.18 & 10.26 & 2.680 \\
\hline $\begin{array}{l}\text { Practiced minor } \\
\text { violence }\end{array}$ & 5.00 & .00 & 5.65 & 1.340 \\
\hline $\begin{array}{l}\text { Practiced } \\
\text { severe violence }\end{array}$ & 6.00 & .00 & 6.02 & .160 \\
\hline $\begin{array}{l}\text { Sexual } \\
\text { experience }\end{array}$ & 38.38 & 9.26 & 37.35 & 7.350 \\
\hline $\begin{array}{l}\text { Coercive sexual } \\
\text { behavior }\end{array}$ & 1.13 & .35 & 1.46 & 1.150 \\
\hline $\begin{array}{l}\text { Sexually violent } \\
\text { pornography }\end{array}$ & 2.00 & 1.00 & 2.13 & .470 \\
\hline $\begin{array}{l}\text { Violent } \\
\text { pornography }\end{array}$ & 2.13 & .35 & 3.48 & .740 \\
\hline $\begin{array}{l}\text { Erotic } \\
\text { pornography }\end{array}$ & 3.75 & 1.16 & 2.62 & 1.060 \\
\hline
\end{tabular}

* means significantly different at $\mathrm{p}<.05$ 
Table 2 - Demographic Characteristics of the Complete Sample

\begin{tabular}{|c|c|c|c|}
\hline & Response & Frequency & Percent \\
\hline \multirow{5}{*}{$\begin{array}{l}\text { Intimate } \\
\text { relationship }\end{array}$} & $<1$ month & 5 & 6.1 \\
\hline & $1-6$ months & 32 & 39.0 \\
\hline & 6 months -1 year & 9 & 11.0 \\
\hline & $>1$ year & 32 & 39.0 \\
\hline & Never & 4 & 4.9 \\
\hline \multirow{5}{*}{$\begin{array}{l}\text { Sexual } \\
\text { intercourse }\end{array}$} & Never & 12 & 14.6 \\
\hline & Occasionally & 29 & 35.4 \\
\hline & Once a month & 10 & 12.2 \\
\hline & Weekly & 29 & 35.4 \\
\hline & Daily & 2 & 2.4 \\
\hline \multirow{5}{*}{$\begin{array}{l}\text { Sexual } \\
\text { partners }\end{array}$} & None & 12 & 14.6 \\
\hline & 1 & 10 & 12.2 \\
\hline & $2-4$ & 35 & 42.7 \\
\hline & $5-9$ & 14 & 17.1 \\
\hline & 10 or more & 11 & 13.4 \\
\hline \multirow{4}{*}{$\begin{array}{l}\text { Fraternity } \\
\text { affiliation }\end{array}$} & Never & 60 & 73.2 \\
\hline & Rushed, not pledged & 6 & 7.3 \\
\hline & Pledged, not active & 3 & 3.7 \\
\hline & Active & 13 & 15.9 \\
\hline \multirow{7}{*}{$\begin{array}{l}\text { Athletic } \\
\text { involvement }\end{array}$} & None & 6 & 7.3 \\
\hline & Informal & 32 & 39.0 \\
\hline & Club sports & 28 & 34.1 \\
\hline & Varsity, (not & & \\
\hline & basketball/football) & 9 & 11.0 \\
\hline & Varsity & 7 & 05 \\
\hline & & & \\
\hline \multirow{4}{*}{$\begin{array}{l}\text { Parental } \\
\text { status }\end{array}$} & Married & 62 & 75.6 \\
\hline & Separated & 4 & 4.9 \\
\hline & Divorced & 14 & 17.1 \\
\hline & Widowed & 2 & 2.4 \\
\hline \multirow{5}{*}{$\begin{array}{l}\text { Living } \\
\text { arrangement }\end{array}$} & Mother \& father & 61 & 74.4 \\
\hline & Mother only & 13 & 15.9 \\
\hline & Father only & 4 & 4.9 \\
\hline & Mother \& partner & 3 & 3.7 \\
\hline & Father \& partner & 1 & 1.2 \\
\hline
\end{tabular}




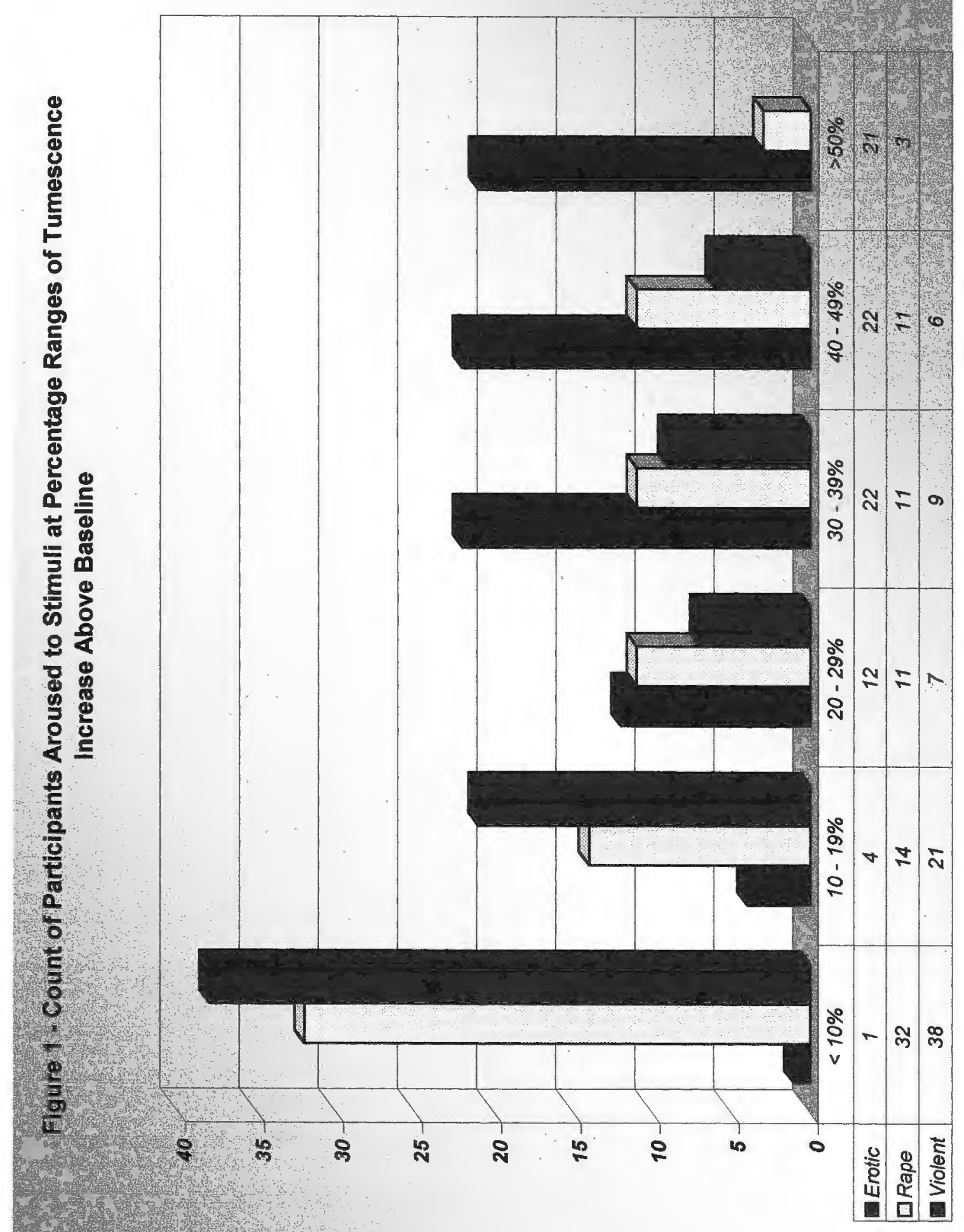


greatest arousal to each of the video stimuli. 67 participants (82\%) were most aroused to the erotic stimulus, $10(12 \%)$ to the rape stimulus, and $5(6 \%)$ to the non-sexual violent stimulus. Demographic and individual difference measures means for these three groups are presented in Table 3. None of the differences were significant.

Coercive sexual behavior.

Responses on the Coercive Sexual Behavior scale were skewed, with most participants denying coercive sexual conduct. 67 participants $(81.7 \%)$ admitted no coercive sexual behavior, only 6 (7.3\%) admitted coercive sexual contact, 6 (7.3\%) admitted rape, 2 admitted sexual coercion, and 1 admitted attempted rape.

\section{Prediction of Sexual Arousal to Erotic, Rape, and Non-sexual Violent}

\section{$\underline{\text { Videos }}$}

Regression analyses of predictors of sexual arousal to stimuli.

In order to identify predictors of sexual arousal to each video, a series of standard multiple regression analyses were performed. In the first analysis prediction of maximum tumescence to the erotic stimulus was represented by the set of individual measures that included age, fraternity affiliation, athletic participation, observed parental verbal aggression, observed parental minor violence, observed parental severe violence, practiced verbal aggression, practiced minor violence, practiced severe violence, sex experience, coercive sexual behavior, erotic pornography, sexually violent pornography, and non- 
Table 3 - Mean Measures by Maximum Arousal to Stimulj

\begin{tabular}{lrrr} 
& $\begin{array}{c}\text { Erotic } \\
\text { Stimulus }\end{array}$ & $\begin{array}{c}\text { Rape } \\
\text { Stimulus }\end{array}$ & $\begin{array}{c}\text { Violent } \\
\text { Stimulus }\end{array}$ \\
\hline Age & 19.48 & 19.30 & 18.80 \\
Fraternity Affiliation & 1.66 & 1.40 & 1.60 \\
Athletic Involvement & 2.70 & 2.80 & 3.20 \\
Observed Verbal Aggression & 11.55 & 10.60 & 13.00 \\
Observed Minor Violence & 6.63 & 7.40 & 7.40 \\
Observed Severe Violence & 6.34 & 7.20 & 6.60 \\
Practiced Verbal Aggression & 10.16 & 10.00 & 12.00 \\
Practiced Minor Violence & 5.55 & 5.90 & 6.40 \\
Practiced Severe Violence & 6.01 & 6.10 & 6.00 \\
Sexual Experience & 37.04 & 39.80 & 36.60 \\
Coercive Sexual Behavior & 1.40 & 2.10 & 1.00 \\
Erotic Pornography & 2.64 & 2.60 & 2.40 \\
Sexually Violent Pornography & 2.16 & 2.00 & 2.00 \\
Violent Pornography & 3.48 & 3.60 & 3.20 \\
\hline
\end{tabular}


sexual violent pornography and did not result in a significant overall stepwise regression, nor did any predictors reach significance.

In the analysis of maximum tumescence to the rape stimulus, the same set of predictors was entered into the equation. The overall stepwise regression was significant for the single predictor of athletic involvement $(R=.31, F(1,80)=$ $\left.8.40, p<.05, R^{2}=.10\right)$. Those men whose participation tends more toward varsity sports, especially football and basketball, more so than those either not involved or involved in club sports, measure greater maximum tumescence to rape $(\beta=.308$, sig. $<.05)$ and account for $10 \%$ of the variation in rape tumescence.

Finally, maximum tumescence to the non-sexual violent stimulus was entered into a stepwise multiple regression analysis with the entire set of measures. The result was a significant overall regression for the single predictor athletic involvement $\left(R=.36, F(1,80)=11.65, p<.05, R^{2}=.13\right)$. In this case it seems that those whose participation tends more toward varsity sports, especially football and basketball, more so than those either not involved or involved in club sports, are more aroused to the non-sexual violent video $(\beta=$ .357 , sig. $<.05)$. This independent variables accounts for about $13 \%$ of the variation in non-sexual violent tumescence.

When physiological tumescence change percents were used in determining regression equations, a significant stepwise regression was reported in terms of tumescence change percent to the non-sexual violent video represented by the single predictor variable athletic involvement $(R=.28, F(1$, 
$\left.80)=6.60, p<.05, R^{2}=.08\right)$. Like regression for tumescence to the rape video, those participants who tend more toward participation in varsity sports, especially football and basketball, more so than those either not involved or involved in club sports, are more aroused proportionately, when adjusted for baseline tumescence, to the non-sexual violent video $(\beta=.276$, sig. <.05) and account for $8 \%$ of the variation in rape tumescence.

Discriminant classification of high and low stimulus arousal.

Another procedure used to describe measures which are most useful in distinguishing groups with greater sexual arousal to watching the various stimuli is discriminant function analysis. This procedure aids both in identifying a combination of factors and in determining how well that particular combination discriminates the outcome. Using a median split grouping procedure for high and low tumescence change to viewing each stimulus, a number of potential predictors were entered into a discriminant analysis. Then, using a criterion of structure coefficient $\geq .30$ (representing the pooled within groups correlations between the potentially discriminating variables and the standardized canonical discriminant function values) less discriminating measures were eliminated, leaving a more parsimonious set of predictor measures that were re-entered into a revised discriminant function analysis.

For tumescence change to viewing the rape video stimulus, the resultant prediction equation, with the associated standardized discriminant function coefficients, included the following measures: athletic participation (.740), observed parental minor violence (.301), and sex experience (.549). About 
three-fifths $(61.7 \%)$ of the original grouped cases were correctly classified by this combined function.

These measures that were identified as more discriminating of the outcome arousal levels were then used as grouping variables in crosstabulation analysis to investigate the odds ratios of the likelihood that high or low scores would predict high or low arousal to either rape or non-sexual violence. ChiSquare tests of equal proportions identified athletic participation as a robust indicator of sexual arousal to both rape $\left(\chi^{2}(1)=7.485\right.$, sig. $\left.<.05\right)$ and nonsexual violent $\left(\chi^{2}(1)=7.765\right.$, sig. $\left.<.05\right)$ stimuli. The odds that a non-varsity athlete in this sample scored high on sexual arousal to the rape stimulus is .757 , whereas the odds that varsity athletes did is 4.333 . The resultant odds ratio of 5.726 suggests that varsity athletes are more than five times as apt to have higher sexual arousal to the rape video. (see Table 4 and Figure 2).

Results for the violent video are quite similar. Here the odds that a nonvarsity athlete in this sample scored high on sexual arousal to the non-sexual violent stimulus is .737 , whereas the odds that varsity athletes did is 4.333 . Again, the resultant odds ratio of 5.881 suggests that varsity athletes have higher sexual arousal to the non-sexual violent video more than five times as often as non-varsity athletes. (see Table 5 and Figure 3).

A Chi-Square test of equal proportions likewise identified participant's age as an indicator of sexual arousal to the non-sexual violent stimulus $\left(\chi^{2}(1)=\right.$ 4.473, sig. <.05). The odds that a participant under 20 years old in this sample scored high on sexual arousal to the violent stimulus is 1.391 , whereas the odds 
Table 4 - Athletic Participation / Rape Tumescence Change Crosstabulation

\begin{tabular}{lllrrr}
\hline \hline & & \multicolumn{3}{c}{$\begin{array}{c}\text { Rape } \\
\text { Tumescence } \\
\text { Change }\end{array}$} & \\
\cline { 3 - 4 } & & Low & High & Total \\
\hline Count & Athletic & Non-varsity & 37 & 28 & 65 \\
& Participation & Varsity & 3 & 13 & 16 \\
\hline \multirow{2}{*}{$\%$ Within } & Athletic & Non-varsity & $56.9 \%$ & $43.1 \%$ & $100.0 \%$ \\
Group & Participation & Varsity & $18.8 \%$ & $81.3 \%$ & $100.0 \%$ \\
\hline \hline
\end{tabular}

Figure 2 - Athletic Participation / Rape Tumescence

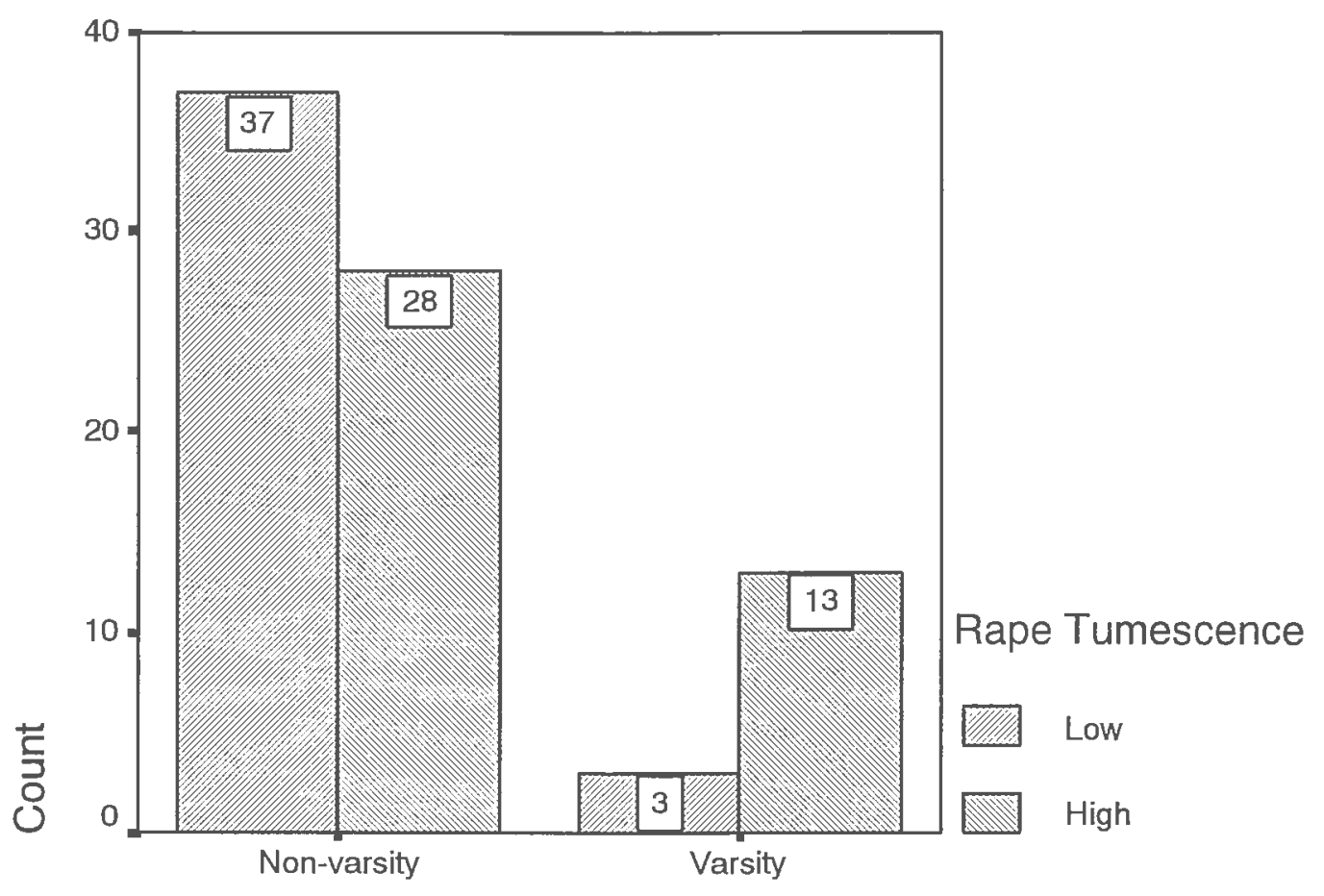

Group by Athletic Participation 
Table 5 - Athletic Participation / Violent Tumescence Change Crosstabulation

\begin{tabular}{lllrrr}
\hline \hline & & \multicolumn{3}{c}{$\begin{array}{c}\text { Violent } \\
\text { Tumescence } \\
\text { Change }\end{array}$} & \\
\cline { 3 - 5 } & & High & Low & Total \\
\hline Count & Athletic & Non-varsity & 38 & 28 & 66 \\
& Participation & Varsity & 3 & 13 & 16 \\
\hline \multirow{2}{*}{ G Within } & Athletic & Non-varsity & $57.6 \%$ & $42.4 \%$ & $100.0 \%$ \\
& Participation & Varsity & $18.8 \%$ & $81.3 \%$ & $100.0 \%$ \\
\hline \hline
\end{tabular}

Figure 3-Athletic Participation/Violent Tumescence

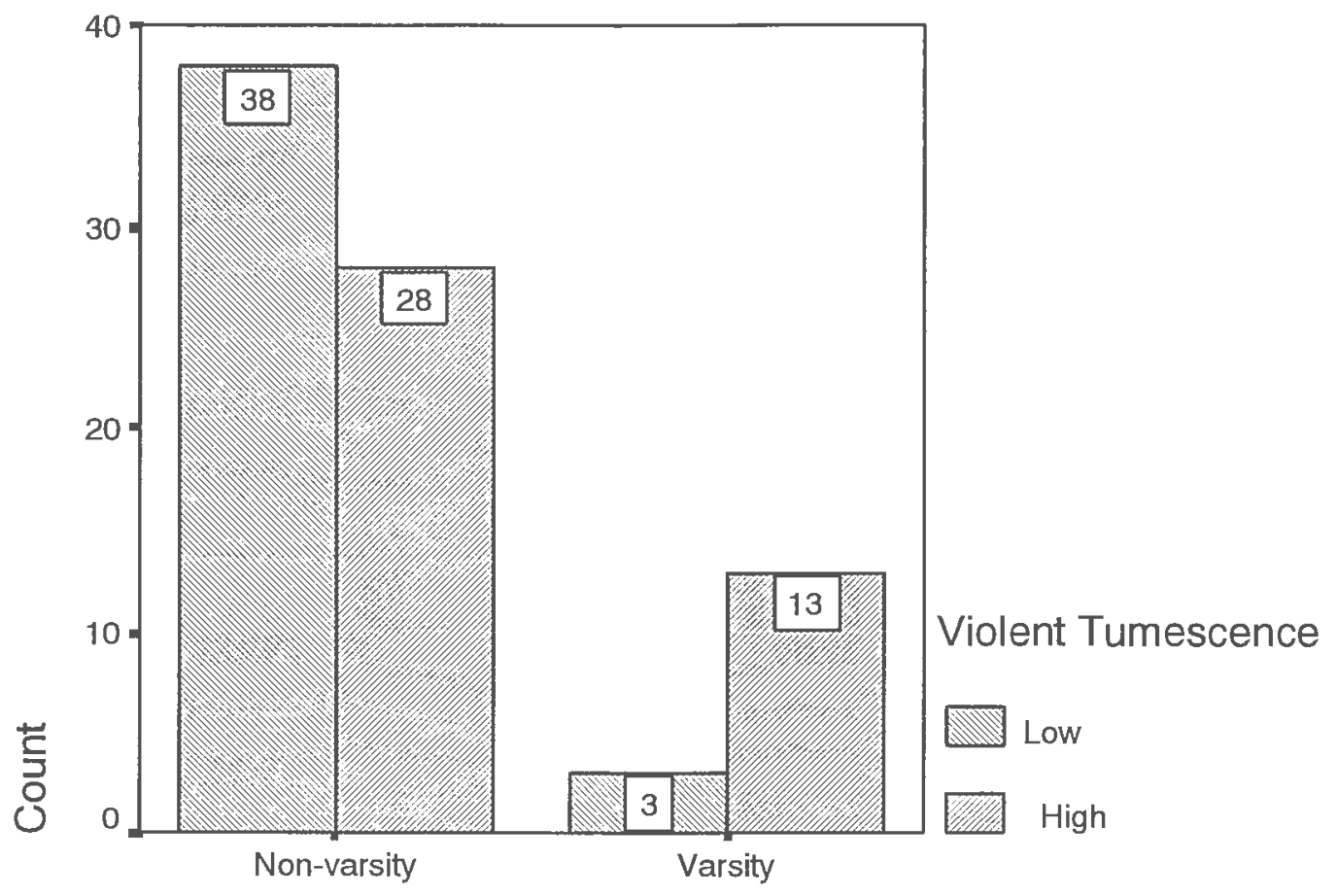

Group by Athletic Participation 
that one over 20 did is .500 . The resultant odds ratio of .359 suggests that younger men are about three times as apt to have higher sexual arousal to the non-sexual violent video. (see Table 6 and Figure 4).

\section{Comparisons of More Dichotomized Subsets of Those Aroused to Non-}

\section{sexual Violence}

In an effort to identify unique characteristics of the subset of participants most sexually aroused by the non-sexual violent video, the entire sample was divided using difference scores between baseline tumescence and maximum tumescence during the non-sexual violent stimulus. The ratio of this difference score to baseline was calculated. Extreme groups were formed by the highest and lowest thirds. This resulted in two equal subsets, one representing the 27 men from the original sample who had the most tumescence change to nonsexual violence, and the other representing the 27 men who had the least.

Comparisons of group means of most and least aroused.

Independent samples $\underline{t}$ tests compared means for the most aroused to non-sexual violence and those least aroused to non-sexual violence for the set of individual difference measures. Significant differences were found for athletic participation $(\mathrm{t}(52)=-2.62, \underline{\mathrm{p}}<.05)$, observed parental minor violence $\mathrm{t}(\mathrm{t}(52)=$ $2.30, \underline{p}<.05)$, and practiced minor violence $(\mathrm{t}(52)=-2.67, \underline{\mathrm{p}}<.05)$. Means and standard deviations for the two groups are presented in Table 7.

Correlations of individual difference measures within subgroups.

Pearson's correlation coefficients were computed to assess the relationship between individual difference measures within each group. 
Table 6 - Age / Violent Tumescence Change Crosstabulation

\begin{tabular}{lllrrr}
\hline \hline & & \multicolumn{3}{c}{$\begin{array}{c}\text { Violent } \\
\text { Tumescence } \\
\text { Change }\end{array}$} \\
\cline { 3 - 5 } & & & Low & High & Total \\
\hline Count & Groups & $<20$ & 23 & 32 & 55 \\
& by Age & $20+$ & 18 & 9 & 27 \\
\hline \% Within Groups by & Groups & $<20$ & $41.8 \%$ & $58.2 \%$ & $100.0 \%$ \\
Age & by Age & $20+$ & $66.7 \%$ & $33.3 \%$ & $100.0 \%$ \\
\hline \hline
\end{tabular}

Figure 4 - Age/Violent Tumescence

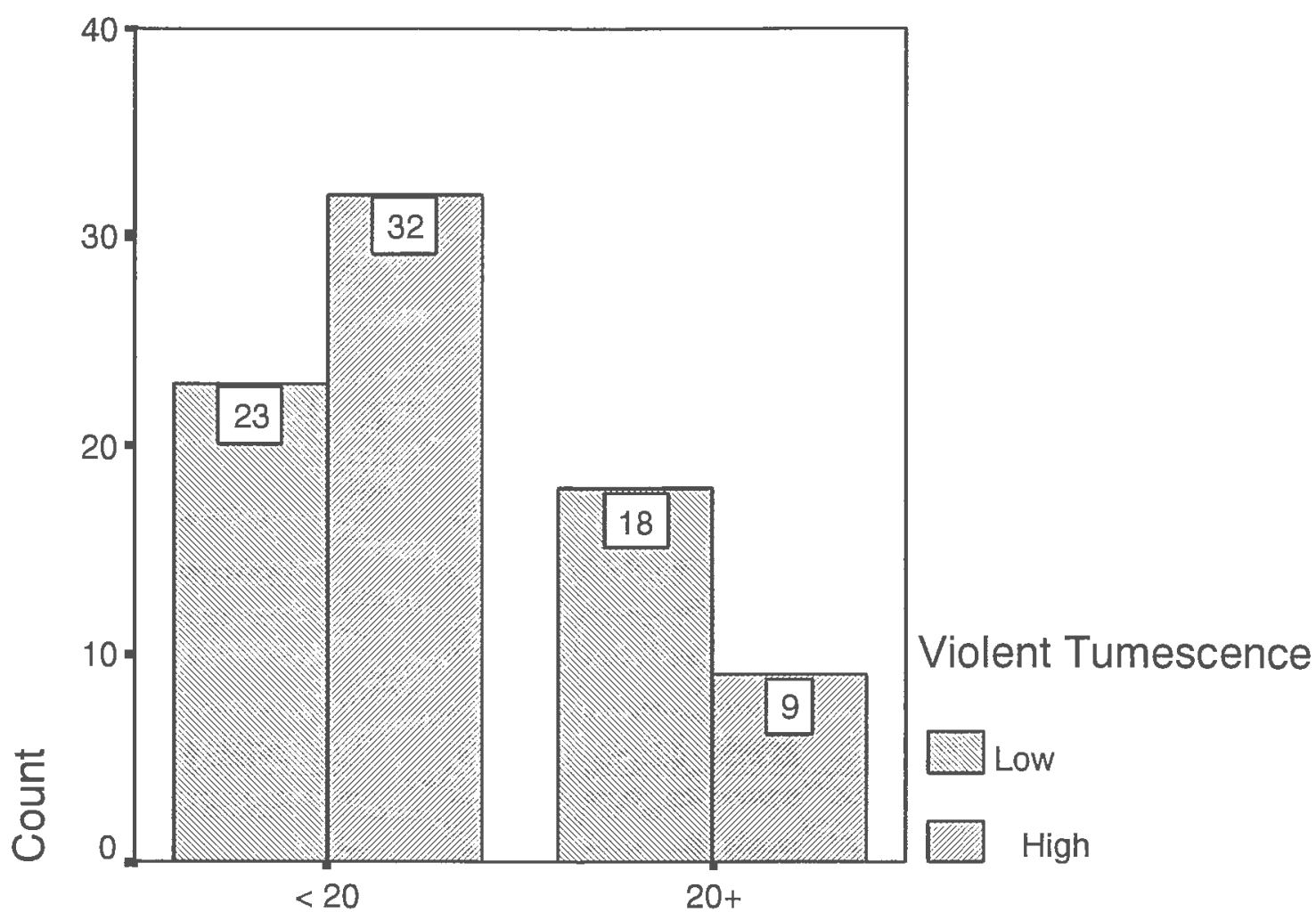

Groups by Age 
Table 7 - Comparison of Highest vs. Lowest Aroused to Violent Video

\begin{tabular}{|c|c|c|c|c|}
\hline & $\begin{array}{l}\text { Lowest } \\
\text { Arousal to } \\
\text { Violence } \\
\text { Mean }\end{array}$ & $\begin{array}{c}\text { Std. } \\
\text { Deviation }\end{array}$ & $\begin{array}{l}\text { Highest } \\
\text { Arousal to } \\
\text { Violence } \\
\text { Mean }\end{array}$ & $\begin{array}{c}\text { Std. } \\
\text { Deviation }\end{array}$ \\
\hline Age & 19.74 & 2.26 & 18.89 & .85 \\
\hline Fraternity affiliation & 1.89 & 1.31 & 1.74 & 1.16 \\
\hline Athletic participation * & 2.48 & .75 & 3.19 & 1.18 \\
\hline Observed verbal aggression & 10.52 & 3.50 & 12.15 & 3.98 \\
\hline Observed minor violence * & 5.74 & 1.51 & 8.22 & 5.39 \\
\hline Observed severe violence & 6.07 & .38 & 7.26 & 3.17 \\
\hline Practiced verbal aggression & 9.70 & 2.45 & 10.48 & 3.15 \\
\hline Practiced minor violence * & 5.19 & .56 & 6.19 & 1.86 \\
\hline Practiced severe violence & 6.00 & .00 & 6.07 & .27 \\
\hline Sexual experience & 36.74 & 6.77 & 36.59 & 7.41 \\
\hline Coercive sexual behavior & 1.48 & 1.19 & 1.59 & 1.31 \\
\hline Erotic pornography & 2.41 & .93 & 2.63 & 1.15 \\
\hline Sexually violent pornography & 2.19 & .56 & 2.11 & .42 \\
\hline Violent pornography & 3.33 & .68 & 3.59 & .89 \\
\hline Rape tumescence change \% & 7.36 & 9.78 & 33.06 & 15.97 \\
\hline $\begin{array}{l}\text { Violent tumescence change } \\
\%\end{array}$ & .27 & 3.39 & 2.35 & 11.08 \\
\hline
\end{tabular}

* means significantly different at $\underline{\mathrm{p}}<.05$ 
Significant associations that were identified were unique to one group or the other, with no significant associations being shared by both groups. Within the group that was least aroused, age was strongly correlated with observed parental minor violence, very strongly correlated with observed parental severe violence, and moderately negatively correlated with the percent of tumescence change to the rape video. Athletic involvement was strongly correlated with both practiced verbal aggression and practiced minor violence. Fraternity affiliation was moderately correlated with sexually violent pornography use, and coercive sexual behavior was strongly correlated with observed parental severe violence.

By contrast, within the group most aroused to the non-sexual violent video, age was moderately negatively correlated to sexual experience and strongly negatively correlated to observed parental verbal aggression. Fraternity affiliation was moderately correlated to coercive sexual behavior and strongly correlated to violent pornography use. Athletic participation was strongly correlated to observed parental severe violence, and practiced severe violence was strongly correlated to erotic pornography use. Coercive sexual behavior was strongly correlated to sexually violent pornography use and very strongly correlated to both erotic and violent pornography use.

When differences between significant high group correlations and low group correlations on the same paired association were compared, a number of significant correlation differences were detected (see Table 8).

\section{Discriminant function analyses.}

In order to identify a combination of factors that discriminate those most 


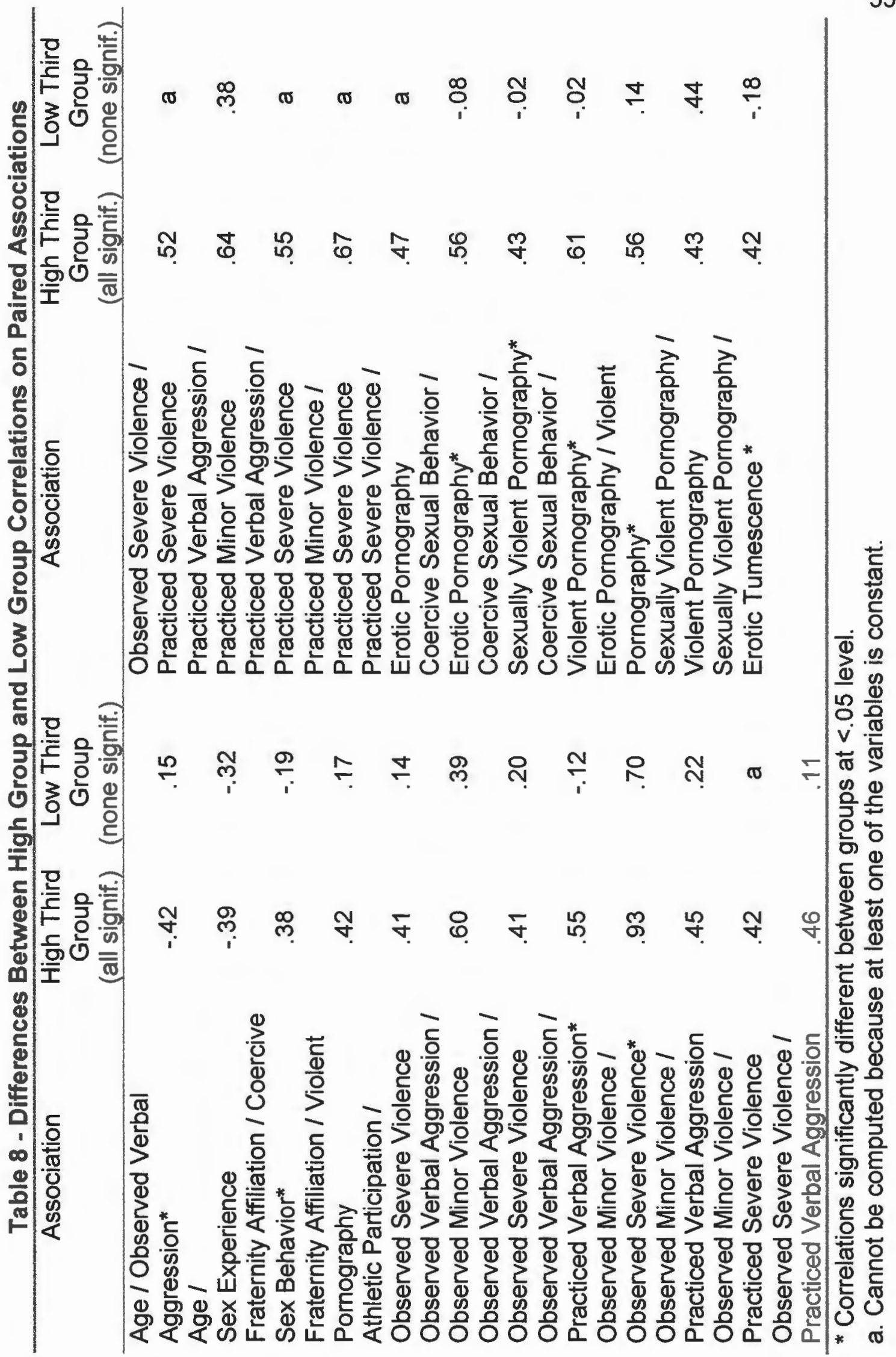


aroused to violence from those least aroused in the trisected sample from which the middle subset had been discarded, classification of these extreme groups was performed whereby a number of potential predictors were entered into a discriminant analysis. Then, using a criterion of structure coefficient $\geq .30$ (representing the pooled within groups correlations between the potentially discriminating variables and the standardized canonical discriminant function values) less discriminating measures were eliminated, leaving a more parsimonious set of predictor measures that were re-entered into a revised discriminant function analysis. The resultant prediction equation contained the following measures with the associated standardized discriminant function coefficients: observed parental minor violence (.622), practiced minor violence (.547), athletic participation (.523), age (-.425), and observed parental severe violence (-.342). Almost three-quarters $(74.1 \%)$ of the original grouped cases were correctly classified by this combined function.

When those functions that were identified as more discriminating were further analyzed with crosstabulations, Chi-Square tests of equal proportions confirmed athletic involvement as a substantial indicator of sexual arousal to violence $\left(\chi^{2}(1)=7.855\right.$, sig. <.05). The odds ratio of 13.000 indicates that varsity athletes are 13 times more apt to be in the group most aroused to the non-sexual violent video as they are to be in the group least aroused to the nonsexual violence. Nearly as robust was the factor of practiced minor violence $\left(\chi^{2}\right.$ $(1)=6.857$, sig. $<.05$; odds ratio $=7.353$ ), indicating more than 7 times the probability that a participant highly aroused to the non-sexual violent video also 
practices minor violence in his interpersonal interactions. Also significant was the factor of observed parental severe violence $\left(\chi^{2}(1)=4.103\right.$, sig. <.05; odds ratio $=7.429$ ), suggesting a 7 times greater chance that those highly aroused to non-sexual violence observed severe violence between their parents.

\section{Correlational Analyses of Associations Among Individual Difference}

\section{Measures}

\section{Observed and practiced aggression and violence.}

Pearson's correlation coefficients were computed to assess the relationship between the three subscale measures of observed parental aggression and violence, observed parental verbal aggression, observed parental minor violence, and observed parental severe violence, the three subscale measures of practiced aggression and violence, practiced verbal aggression, practiced minor violence, and practiced severe violence, and coercive sexual behavior. A correlation matrix is presented in Table 9.

The three observed conflict subscales were all significantly correlated with each other. Observed parental verbal aggression had a very strong correlation with observed parental minor violence and a moderate correlation with observed parental severe violence, while observed parental minor violence had a very strong correlation with observed parental severe violence. Likewise, all three practiced aggression and violence subscales were significantly correlated with each other. Practiced verbal aggression had a moderate correlation with both practiced minor violence and practiced severe violence, while practiced minor violence had a very strong correlation with practiced severe violence. 
Table 9 - Correlations of Observed and Practiced Conflict Tactics

\begin{tabular}{lllllll}
\hline & OVERB & OMINV & OSEV & PVERB & PMINV & PSEV \\
OVERB & 1.00 & $.54^{\star \star}$ & $.30^{\star \star}$ & $.28^{\star \star}$ & .20 & .16 \\
OMINV & & 1.00 & $.88^{\star \star}$ & $.31^{\star \star}$ & $.22^{\star}$ & $.42^{\star \star}$ \\
OSEV & & & 1.00 & $.30^{\star \star}$ & .18 & $.55^{\star \star}$ \\
PVERB & & & 1.00 & $.38^{\star \star}$ & $.37^{\star \star}$ \\
PMINV & & & & & 1.00 & $.58^{\star \star}$ \\
PSEV & & & & & & \\
\hline
\end{tabular}

**. Correlation is significant at $<.01$ level (2-tailed).

*. Correlation is significant at $<.05$ level (2-tailed). 
Between observed subscales and practiced subscales, a number of significant correlations were observed. Observed parental verbal aggression, observed parental minor violence, and observed parental severe violence all had significant, moderately weak or moderate correlations with practiced verbal aggression. Observed parental minor violence had a significant, moderately weak correlation with practiced minor violence, but a significant, strong correlation with practiced severe violence, while observed parental severe violence had a significant, very strong correlation with practiced severe violence. Considering the quantity of correlations simultaneously considered, a Bonferroni adjustment to the probabilities was performed, only resulting in dropping from significance the moderately weak correlation found between observed parental and practiced minor violence. All other comparisons remain after such adjustment. Most of the observed and practiced subscale measures were significantly related, thus confirming hypothesis 1 , which predicted that observed and practiced aggression and violence would be related.

\section{Coercive sexual behavior and practiced aggression and violence.}

Do men who report coercive sexual behavior also report practiced aggression and violence? High and low groups were formed on coercive sexual behavior. If the participant reported any coercive sexual behavior, he was assigned to the high coercive sexual behavior group $(n=15)$. If he reported no coercive sexual behavior, he was assigned to the low coercive sexual behavior group $(n=67)$. Means for high and low coercive sexual behavior groups were compared with independent samples tests for each of the individual difference 
measures practiced verbal aggression, practiced minor violence, and practiced severe violence. Analysis found no significant differences between those admitting coercive behavior and those not, consequently hypothesis 2 was not confirmed.

\section{Stimulus Measures}

\section{Stimulus effect.}

Since baseline measures of tumescence proved to be equivalent to neutral measures of tumescence (baseline tumescence: $\underline{M}=94.48, \underline{S D}=11.71$; neutral tumescence: $\underline{M}=93.40, \underline{S D}=10.95$; paired samples $\underline{t}(81)=1.43, \underline{p}=$ .16), neutral tumescence was taken as a zero point in a test of significant differences on measures of the maximum tumescence to each of the other stimuli. Erotic, rape, and non-sexual violent tumescence measures were all significantly different from neutral tumescence, whether measured as a raw score $(\underline{M D}=39.01$, paired samples $\underline{t}(81)=25.54, \underline{p}<.05$, for millimeters of erotic tumescence change; $\underline{M D}=18.81$, paired samples $\underline{t}(81)=10.55, \underline{p}<.05$, for millimeters of rape tumescence change; and $\underline{\mathrm{MD}}=13.58$, paired samples $\underline{\mathrm{t}}(81)=$ $8.33, \underline{\mathrm{p}}<.05$, for millimeters of non-sexual violent tumescence change) or as a percentage of increase over neutral $\underline{M D}=42.16$, paired samples $\underline{t}(81)=25.18$, $\underline{\mathrm{p}}<.05$, for erotic tumescence percent change; $\underline{\mathrm{MD}}=20.04, \underline{\mathrm{t}}(81)=10.80, \underline{\mathrm{p}}<.05$, for rape tumescence percent change; and $\underline{\mathrm{MD}}=14.39, \underline{\mathrm{t}}(81)=8.64, \underline{\mathrm{p}}<.05$, for non-sexual violent tumescence percent change). (see Figures 5 and 6). Thus, hypothesis 7 was confirmed. 
Figure 5 - Tumescence by Stimulus

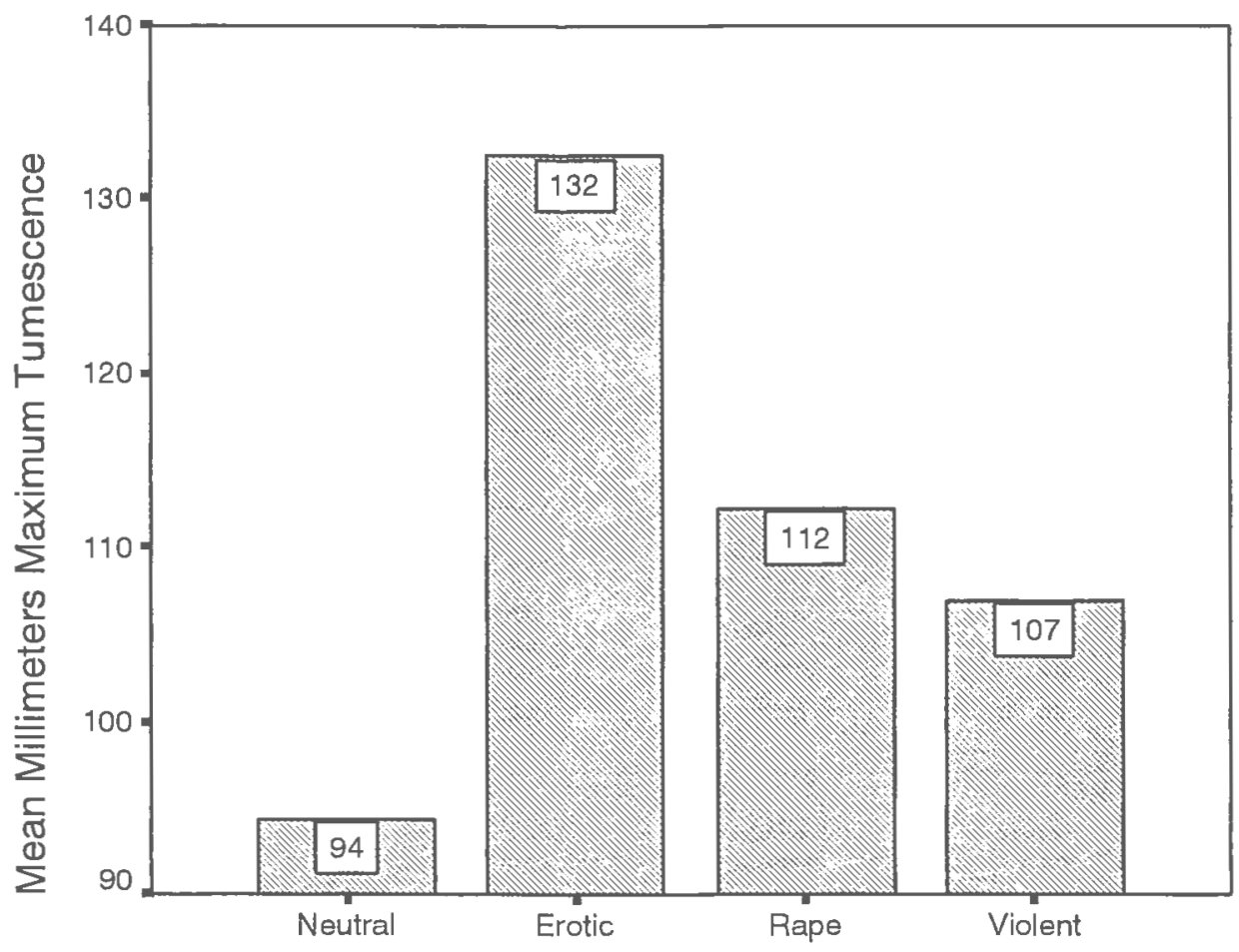

Figure 6 - Tumescence Percent by Stimulus

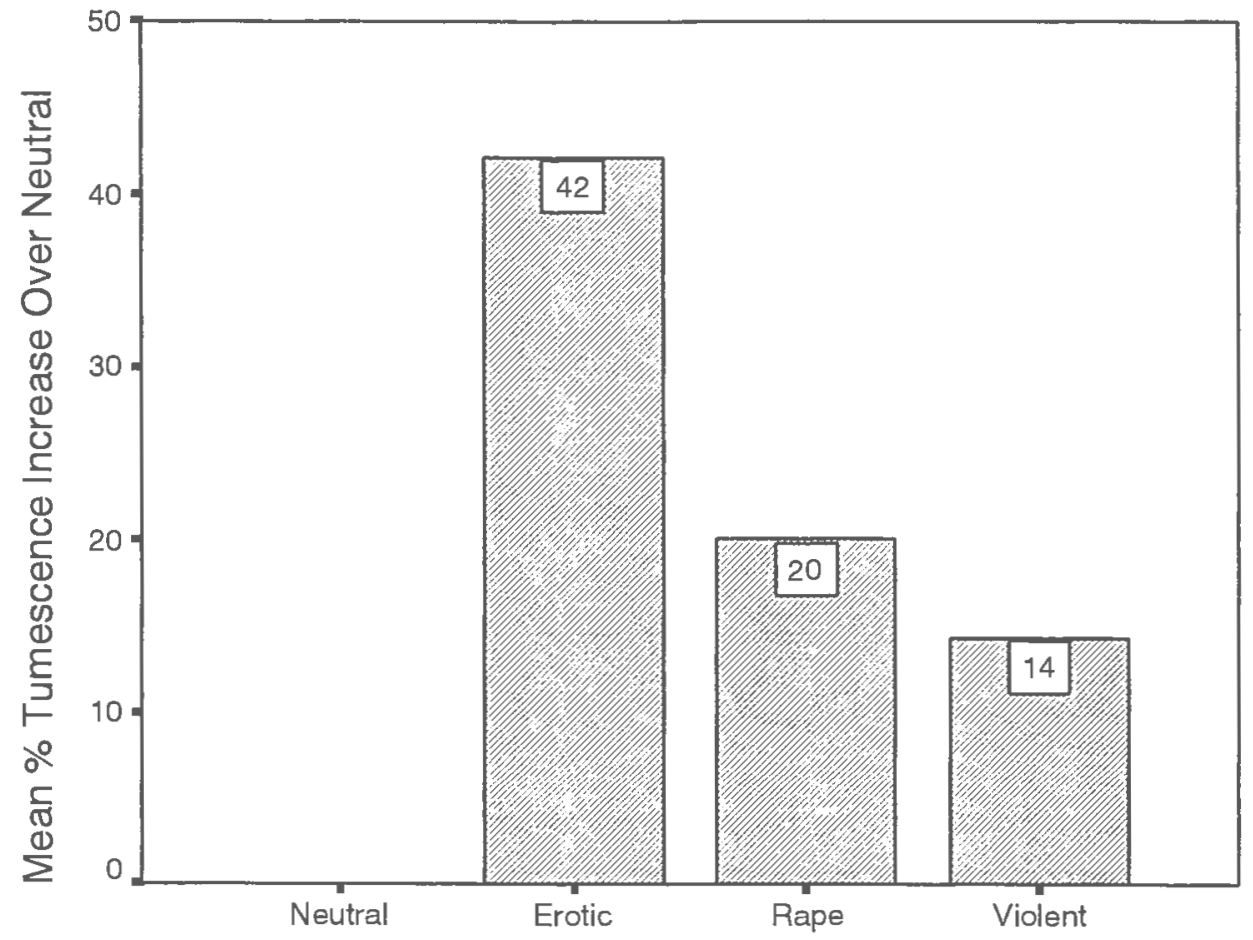




\section{Order Effects.}

In order to investigate the possible "priming" effect of any one of the stimulus presentations on those that followed, in terms of the stimulus tumescence adjusted percentage scores, an ANOVA found a significant effect for video sequence only with arousal to the erotic video, $\underline{F}(5,76)=3.09, \underline{p}<.05$. Post hoc multiple comparisons of video sequences on erotic tumescence change percent identified significantly different erotic arousal between two pairs of video sequences. The sequence neutral, rape, violent, erotic (where the erotic arousal was 'primed' by both rape and non-sexual violent videos) was associated with a significantly higher erotic arousal than either the sequence neutral, violent, erotic, rape (where the erotic arousal was only 'primed' by the non-sexual violent) or the sequence neutral, erotic, violent, rape (where the erotic arousal was not 'primed' by either rape or non-sexual violent videos). Hypothesis 5 was thus confirmed, but with some qualification.

Individual differences and sexual arousal to rape and non-sexual violence.

Using a median split to group scores on the summed total of observed parental verbal aggression, observed parental minor violence, and observed parental severe violence, the summed total of practiced verbal aggression, practiced minor violence, and practiced severe violence, as well as coercive sexual behavior, a series of three repeated measures ANCOVAs were performed. The independent grouping factors were each of the summed subscales and coercive sexual behavior. Neutral tumescence was used as a covariate. The stimulus effect was significant for observed parental aggression 
and violence, $\underline{E}(2,156)=4.17, \underline{p}<.05$, and practiced aggression and violence, $\underline{F}(2,156)=3.72, \underline{p}<.05$. No significant main effects or interactions were found.

Thus, tests of the significance of group differences between observed parental conflict, practiced conflict, or coercive sexual behavior and participants' physiological sexual arousal to video images of either rape or non-sexual violence fail to confirm hypotheses 3,4 , and 5 .

\section{Physiological and subjective measures of arousal.}

The association between subjective sexual arousal, as measured by lever adjustments, and physiological tumescence change percents was determined using Pearson's correlation coefficients. Participants' tumescence change percents in response to the rape and non-sexual violent videos were significantly correlated with subjective arousal to these stimuli $\underline{r}=.44, \underline{p}<.01$ and $\underline{r}=.46$, $\underline{p}<$ .01 , respectively). (see Table 10). Erotic correlation was not significant. A relationship between the construct measures of physiological and subjective sexual arousal to observing the erotic, rape, and non-sexual violent stimuli presentations that was predicted in hypothesis 8 was thus confirmed.

Sex experience and pornography use interaction and sexual arousal to rape and non-sexual violence.

A significant positive relationship was predicted in physiological arousal to rape and non-sexual violent videos between participants who were both less experienced sexually and more frequent users of pornography. When the entire sample was divided into both high and low pornography use and high and low sexual experience, it resulted in a low experience / high pornography cell size of 
Table 10 - Tumescence / Lever Correlations

\begin{tabular}{|c|c|c|c|c|c|c|}
\hline & $\begin{array}{l}\text { Erotic } \\
\text { Tumes. } \\
\%\end{array}$ & $\begin{array}{l}\text { Erotic } \\
\text { Lever }\end{array}$ & $\begin{array}{l}\text { Rape } \\
\text { Tumes. } \\
\%\end{array}$ & $\begin{array}{l}\text { Rape } \\
\text { Lever }\end{array}$ & $\begin{array}{l}\text { Violent } \\
\text { Tumes. } \\
\%\end{array}$ & $\begin{array}{l}\text { Violent } \\
\text { Lever }\end{array}$ \\
\hline $\begin{array}{l}\text { Erotic } \\
\text { Tumescence \% }\end{array}$ & 1.00 & .19 & .17 & -.11 & .07 & -.12 \\
\hline Erotic Lever & & 1.00 & .03 & $.27^{\star}$ & .03 & $.24^{\star}$ \\
\hline $\begin{array}{l}\text { Rape } \\
\text { Tumescence \% }\end{array}$ & & & 1.00 & $.44^{\star \star}$ & $.66^{\star \star}$ & $.32^{\star}$ \\
\hline Rape Lever & & & & 1.00 & .21 & $.55^{\star \star}$ \\
\hline $\begin{array}{l}\text { Violent } \\
\text { Tumescence \% }\end{array}$ & & & & & 1.00 & $.46^{\star \star}$ \\
\hline Violent Lever & & & & & & 1.00 \\
\hline
\end{tabular}

** Correlation is significant at $<.01$ level (2-tailed).

${ }^{*}$ Correlation is significant at <.05 level (2-tailed). 
25. When these high pornography/low experience men were compared to a subset of the remainder of the sample, that is, men either high in both pornography use and sexual experience, low in both, or low in pornography use and high in sexual experience, independent tests on these two groups in terms of physiological arousal to rape or violence were not significant. Thus, from a group differences point of view, hypothesis 9 was not confirmed. 


\section{DISCUSSION}

The major focus of this study was to investigate predictors of sexual arousal to rape and non-sexual violent videos in a sample of undergraduate men. It was predicted that an important part of this process of discriminating those sexually aroused from those who were not might be explained theoretically by using a social learning paradigm, in which aggression and violence observed between one's parents and aggression and violence practiced in interpersonal relationships, and more intimately in sexual interactions, would be related to sexual arousal. Growing up in a home where aggression and violent tactics were common is expected to increase the probability that these tactics would become part of a young man's repertoire, and that the verbal aggression and physical violence he saw would be associated with verbal aggression and physical violence that he practices. It would follow that sexual access issues would be handled using similar tactics and that coercive sexual behavior would be associated with those conflict tactics as well.

It was also predicted that behaviors that had their roots in modeling this earlier observed conflict could be amplified through a combination of factors that include the use of pornography and its interaction with sexual inexperience. Here it was expected that some young men might turn more toward vicarious sexual interactions through media than toward developing real-life intimate relations. Then the level of arousal to sexually aggressive and non-sexual violent videos might be influenced by the lessons of pornography more than by 
the lessons of real life, resulting in elevated arousal, compared either to men who were more experienced sexually or less frequent users of pornography.

Finally, since the search for differential characteristics that might predict arousal to aggression and non-sexual violence is still somewhat speculative, other secondary, ancillary factors were proposed as having some predictive ability. Thus fraternity membership, athletic team involvement, and other relationship factors were considered in determining a set of predictors to such arousal.

In the attempt to characterize those men who are sexually aroused to either a rape video or non-sexual violent video, it is notable that in this sample of 82 participants, using a quite conservative level of at least a $20 \%$ increase over tumescence measured while watching a neutral video, 36 men were aroused by rape, and 23 men were aroused by non-sexual violence against a woman. One could argue that the sexualized nature of the interaction in the rape video, though it in no way depicted consent from the woman, may have been linked for some individuals to images that were identified with aggressive consensual sex, but this was clearly not the case in the non-sexual violent video. There, a sobbing, obviously unwilling woman, with blood running from a cut on her lip, constantly struggles to get away from the onslaught of physical abuse. Sexual arousal by this video treads heavily on acceptable cultural norms. Even more alarming, perhaps, is the fact that five men in the sample were most sexually aroused by this scene, and ten men were most sexually aroused by the rape scene. Non-sexual violence or aggression or dominance for these men is 
identified with stronger sexual arousal than a highly erotic scene of equal, mutually consenting sexual expression.

When asked about coercive sexual behavior that they practice in their intimate relations, the men in this sample admitted to 15 acts of sexual coercion, ranging on a continuum from the least coercive behavior, pressuring or using one's position of authority to fondle, kiss, or pet an unwilling woman, through the most coercive, the use of drugs or physical force to have sexual intercourse with a woman against her will. Such incidence reports are probably quite conservative, given that incidence of sexual coercion have been reported by $35 \%$ of women medical students in one sample (McConaghy, \& Zamir, 1995) and $22 \%$ of women psychology students in another (Struckman-Johnson, 1988). The primary focus of this study was on the subset of individuals who were sexually aroused by non-sexual violence, looking for characteristics that might help predict such behavior.

With the caveat that this sample only contained 16 varsity athletes, it was still clear that participating in varsity basketball or football, more so than either not being involved in sports or being involved in club sports, seems to be strongly identified with one's becoming more aroused to images of either rape or nonsexual violence. In terms of sexual arousal to non-sexual violence alone, the association is even stronger when it is in a younger than average varsity athlete who watched violence being used by parents to deal with conflict. Sexual arousal by the rape scene was predicted by a combination of this varsity athletic team participation as well as observing minor violence between one's parents 
and having experienced a greater variety of sexual experiences. At the same time, sexual arousal to non-sexual violence was best discriminated by a combination of varsity athletic team participation, observing parental violence, and being younger than the average participant. Generally athletic participation stood out as a robust indicator of sexual arousal to both rape and non-sexual violence, since varsity athletes in this sample were more than five times as likely to show higher sexual arousal (tumescence) to these two videos. Similarly, it was found that younger men were about three times as likely to have higher sexual arousal to the non-sexual violent video.

When the entire sample was divided into extreme groups, that is the highest third of the men most aroused to violence being compared to the lowest third of the men so aroused, quite different patterns of association with other measures were identified, painting quite different pictures of sub-sample characteristics. In those most aroused, the younger men in the group reported a somewhat less varied repertoire of sexual experiences, as might be expected simply in terms of their having had quantifiably less opportunity to practice these behaviors. They also reported a quite high incidence of having observed verbal aggression between parents. Within those who were affiliated with a fraternity, individuals in this group were quite frequent users of violent pornography and were more apt to admit to using some sort of coercive sexual behavior with unwilling sexual partners. Regardless of fraternity affiliation, these sexually coercive participants reported much greater use of a variety of pornography, erotic, sexually violent, and violent. Varsity athletes who were most aroused to 
violence also reported having observed significantly more severe violence in their parents' conflict, whereas among all of those in this sub-sample, those who practiced more severe violence in their own interpersonal relations reported a much higher use of erotic pornography.

This pattern was contrasted with characteristics of the extreme group least aroused to violence. Contrary to general findings with the entire sample, older men in this group reported having observed more violence in their parents' conflicts and being significantly less aroused to the rape video as well. In this regard, it would seem that the violence that was observed between parents in this sub-sample was not associated with sexual arousal either by the sexually violent or non-sexual violent scenes. Consistent with the robust nature of varsity athletic involvement, even in this group least sexually aroused to non-sexual violence, there was a greater chance that varsity athletes practiced both verbal aggression and minor violence in their interpersonal relations. As with the entire sample, fraternity affiliation in this sub-sample was only identified with greater use of sexually violent pornography. And, finally, those who did admit to some coercive sexual behavior were most apt to be those who observed more severe violence between their parents.

Grouping participants according to individual difference measures instead of outcome measures yielded little by way of characterization. Predictions that practicing more aggression or violence or more coercive sexual behaviors would influence one's sexual arousal to watching rape or violent videos were not 
confirmed. Those who admitted using coercive sexual tactics, likewise, demonstrated no statistically different reactions on measured sexual arousal.

What is notably not evident in this sample are associations between fraternity affiliation and any of the coercive individual difference measures or arousal by scenes of rape or non-sexual violence. The only significant association here that involves fraternity affiliation is a greater frequency of viewing sexually violent pornography. This finding confirms other research (e.g., Koss \& Gaines, 1993) and suggests that the association between fraternity affiliation and sexual aggression, or even arousal to such aggression, may be more due to an association with other factors like alcohol consumption or allmale peer groups, issues beyond the scope of this study.

Confirming the first hypothesis, all three categories of observed conflict, verbal aggression, minor violence, and severe violence, were significantly related to each other. Even though the frequency of observing verbally aggressive tactics was reported much higher than observing acts of violence, and observing episodes of severe violence was reported much less, it was clear that these tactics that were observed being used by men's parents to deal with conflict represented a related continuum. Similarly, the same categories, when applied to one's own practice of conflict in interpersonal relations, were significantly related to each other, also forming a continuum of related practices. Aggression, minor violence, and severe violence do not seem to occur in isolation, whether observed in one's family of origin or practiced in one's interpersonal relationships. 
Social learning theory predicts that there will be significant associations between conflict tactics that one applies in the arena of interpersonal relations and those tactics that were observed being practiced between parents. Measures of association in this sample do, in fact, suggest some degree of confirmation of social learning theory. When you consider the effect of watching parents deal with conflict by attacking each other to the extent of beating, throwing objects, or assaulting the other with a weapon, it comes as no surprise that the strongest associations seem to be between observing such extreme scenes and practicing those same tactics oneself. Even the observation of minor acts of violence between one's parents, where the physical damage perhaps was not so extreme, seemed to be associated quite strongly with practicing severe violence. Less extreme tactics were less effective models of behavior, demonstrating significant but much weaker associations with ones own verbal aggression or use of minor violence.

It may well be that verbal aggression and even some forms of minor violence are so commonplace in family conflict that their influence is negligible as a model for children's own behavior. Only when violence is expressed between parents in its more destructive forms does it seem to be salient enough to play a part in actions resembling intergenerational transmission of behavior. Thus, observing aggression and violence seems to be associated with the more severe types of violence, and the prediction of a relationship between observed aggression and violence and practiced aggression and violence is confirmed at its more severe levels. 
When the focus was more specifically on the tactics employed in gaining sexual access, this sample of men demonstrated a predictable degree of coercive behavior as well. Approximately one of every five men in this sample admitted to using some form of coercive tactic to gain sexual access to a reluctant partner. This confirms the frequencies cited in prior findings with nonincarcerated populations (Briere \& Malamuth, 1983; Craig, Kalichman, \& Follingstad, 1989; Koss, Gidycz, \& Wisniewski, 1987). Interestingly, this group was not hierarchically arranged along a continuum, as one might expect. They expressed as much a tendency to use what might be considered less extreme behavior (i.e., verbal pressure, misuse of their authority, threats of harm, or actual physical force, in order to gain access to fondling, kissing, or petting, but not intercourse) as they did to engaging in the most extreme forms of sexual aggression (employing the threat of force, the actual use of physical force, or administering drugs or intoxicants for the purpose of engaging in vaginal, oral, or anal intercourse with an unwilling victim). Only a few individuals admitted behaviors that fell between these two extremes, that is using the above noted techniques in an unsuccessful attempt at intercourse or engaging in sexual intercourse subsequent to the use of menacing verbal pressure or the misuse of authority.

The unequal proportions of the number of participants in the coercive vs. the non-coercive groups thwarted the attempt to label differences statistically significant, but certain patterns were clear. In terms of practicing verbal aggression in non-sexual conflict, where the non-coercive group was more 
evenly split between those using more and those using less verbal aggression, the coercive group was $50 \%$ more apt to report higher frequency of verbal aggression in their own interpersonal relations.

More noteworthy than describing differences between coercive vs. noncoercive groups, perhaps, is the quantifiable reality of the fact that one man in five admitted using such tactics and that this sample included a sizeable number of admitted rapists. However, the predicted group differences based on coercive sexual behavior ultimately could not be statistically confirmed.

As predicted, the participants demonstrated significantly greater physiological sexual arousal while watching each of the experimental stimuli, erotic, rape, and non-sexual violent, than while watching a neutral video. The magnitude of the response also resulted in a predictable hierarchical order, namely this sample of men generally found the erotic video to be the most sexually arousing, the rape video somewhat less sexually arousing than the erotic, and the non-sexual violent video slightly less sexually arousing than the rape, but still proportionately greater than to the neutral.

Stimulus presentations were randomly assigned to participants due to a concern over there being a priming effect, one stimulus either enhancing or degrading the response to the stimulus that followed. Considering the men's responses to both rape and non-sexual violent stimuli, the particular order that these were presented to them did not seem to make a significant difference. However, when the mean responses to watching either the rape video or the non-sexual violent video were plotted against each other according to those 
different orders, a consistent pattern did develop, especially in response to the latter. In the overall sample, there was a consistency displayed whereby prior exposure to both erotic and rape videos seriously degraded the participant's arousal to the non-sexual violent video that followed. Arousal was most enhanced by prior exposure to erotic alone, but collectively, either order of presentation that began with the non-sexual violent video, without any other sexual or sexually aggressive stimulus prime, resulted in the greatest sexual arousal. When the sample was divided into extremes of highest sexual arousal by the non-sexual violent video and lowest sexual arousal by the non-sexual violent video, the group with lowest sexual arousal seemed fairly equally aroused regardless of where in the sequence of stimulus presentation the non-sexual violent video came. There was a slight enhancement effect of sexual arousal to the non-sexual violent video if it was immediately preceded by the erotic video. But in the group showing highest arousal to the non-sexual violent video, responses to stimuli that followed were clearly amplified when the non-sexual violent video appeared first in the sequence. Thus, twice the degree of sexual arousal by the non-sexual violent video was recorded if that stimulus was first in sequence than if it was primed by appearing either after the erotic video or after the rape video.

It would seem that, in this sample, men were most sexually aroused by a non-sexual violent image when they had not been distracted by seeing other sexual images previously, and, in fact, were the least aroused when they had 
been the most distracted by the sexual and sexually aggressive scenes. This finding confirms the prediction of an order effect in this study.

It was expected that subjective perception of maximum sexual arousal would correspond, for the most part, with maximum physiological increase in penile tumescence. In fact, associations were quite strong between the two measures for both the rape stimulus and the non-sexual violent stimulus, at least partially confirming our prediction. On the erotic stimulus, however, no such association was noted. One might speculate that the magnitude of the response to the erotic video was itself a distracter from the task of monitoring selfperceived arousal.

It was predicted that participants who were less experienced sexually and who used pornography more frequently would most probably demonstrate higher sexual arousal to rape and non-sexual violent images. When this group was compared with either more sexually experienced men or those less experienced who also used pornography infrequently, the overall group differences were not found to be significant. Consequently, that prediction was not supported.

\section{Limitations of the Study}

Human sexuality studies have a unique set of complexities due to their intimate, secretive, cultural, political, social, and legal nature. A positivist approach that is based on observation and experimentation, built around concepts, and guided by propositions in order to explain the phenomena of sexuality can miss some of the multi-dimensionality of the variety of human sexual experience. A caution expressed by Weis (1998a) is well-taken when he 
suggests that scientific theorists, and especially sex theorists, need to "recognize the contextuual nature of science and the multiplicity of meanings assigned to the phenomena studied." (p. 3). Social learning is much more complex than the simple linear relation that may be implied by this research. Others have suggested that multiple variables and their interactions may be more appropriate directions for research into precursors of sexually aggressive behavior than sexual arousal alone (Hall \& Hirschman, 1991; Hall, Shondrick, \& Hirschman, 1993; Malamuth, 1986).

Kolbo, Blakely, and Engleman (1996) note quite emphatically that much of the research on sexuality is guided by social learning theory (especially Wolfe, Jaffe, Wilson, \& Zak, 1985), but conclude that a linear social learning model is not adequate for explaining the relationship between children's witnessing domestic violence and their subsequent development. It has been suggested that more attention needs to be focused on mediating variables of frequency and duration of exposure and the severity of the violence witnessed (Christopoulos et al., 1987; Hughes, Parkinson, \& Vargo, 1989; Jouriles, Barling, \& O'Leary, 1987). Furthermore, even where causality is not inferred, the directionality of the influence in associations can be questioned. Witnessing aggression and violence in one's family of origin can be as much a deterrent as a model for imitation, a complex blend of habituation and dishabituation. It is important to remember that not all child witnesses of parental conflict demonstrate later problems. Jouriles, Murphy, and O'Leary (1989) noted that some 50 percent of the children from maritally aggressive homes in their sample did not report 
problems at clinical levels. In attempting to identify protective competencies that shield children from some of the negative effects of such conflict in the home, O'Brien, Margolin, and John (1995) focused on children's reports of coping strategies that they utilize in response to marital conflict and found that the child's use of coping strategies that involve them in the parents' conflict predicts maladjustment, while distancing coping skills predict decreased levels of such maladjustment.

In all of the complexity of the human experience, another characteristic that is brought to any investigation is the ethnic diversity of the participants. Due to the limited focus of this study and the need to keep stimuli to a minimum, a conscious decision was made to admit a heterosexual, White bias in the selection of stimuli. This limits the scope of the application of findings, but leaves the door open for future replications taking ethnicity and sexual orientation into consideration.

Another criticism often leveled against laboratory investigations of sexual arousal or aggression and violence is the inability of a laboratory setting to begin to duplicate the social context of more naturalistic settings. Certainly sitting alone in the stark, controlled atmosphere of a laboratory, with a band around his penis, manipulating a lever is probably an encounter with sexual arousal that is quite distinct from a young man's typical sexual experience. At another level, the level of realism that can be expected from commercially available videos can also limit the naturalistic nature of the experience. Understandably, legal limitations restricted access to the most realistic video scenes of rape and non- 
sexual violence, further distancing laboratory results from what might be expected if it were possible to replicate more closely the reality of sexual aggression and violence. In fact, were such videos available, serious ethical issues would be raised over their use in research.

A further limitation of this study, one that has been addressed in other research (Barongan \& Hall, 1995; Irwin \& Gross, 1995; Saris, 1996; Weinberg, Lottes, \& Gordon, 1997), is the effect of participants' habituation to depictions of sexual violence or non-sexual violence in light of the media onslaught that confronts individuals in our culture every day. Given the ubiquitousness of sexual and non-sexual violent images that at times seem to characterize the music, television, and film of a whole generation, exposure to the stimuli used in this study may be considered quite conservative when compared to the degree of explicit sexual and non-sexual violent 'normal' fare that participants regularly view.

Finally, even though some effort was made methodologically to account for differences between those who completed the entire study and those who declined participation in the physiological portion, the possibility still exists that the results represent a volunteer bias when considering application to the entire campus community. Recruiting posters clearly stated that the theme of the research was sexual in nature and may have discouraged a substantial portion of the campus population from volunteering. In addition, issues involving varsity athletes might be better addressed in a quasi-experimental setting with 
comparisons between equal groups of varsity athletes and non-varsity athletes on a number of relevant factors.

\section{Implications for Future Research}

The social learning paradigm was confirmed in this study, but further research should more closely investigate the modeling of parental conflict tactics. Whereas parental conflict was collapsed across gender, this is certainly one area where significant differences may be found. It would be valuable to investigate not just same gender or cross-gender modeling, but what predictors, sociological, psychological, or affective, might determine a child's identification with a parental model in terms of observed aggression and violence.

Experimental manipulation of stimulus characteristics beyond the limited White heterosexual confines of this study could expand our understanding of sexual arousal to a variety of ethnic models and to a variety of depictions of other sexual orientations.

Additional research could also aid in discriminating other salient factors that may be even more closely aligned with sexual arousal. Expanding on Brownmiller's (1975) focus of gender conflict, power, and dominance in sexuality, Weis (1998b) argues that issues of power, conflict, and exploitation are obvious characteristics of sexual relationships and warns that understanding sexuality requires examining the role that power plays in relationships. It could well be that men's sexual arousal to non-sexual violence masks an underlying titillation with domination.

With confirmation of the robust association between varsity athletic 
participation and sexual arousal to violence, the stage seems to have been set for the establishment of a logical starting point for intervention studies aimed at curbing sexual aggression against women.

From a theoretical point of view, however, any one of these approaches may prove to be too simplistic and may be doomed as too focused on one particular aspect of aggression or violence and its association with sexual arousal to be able to properly identify the reality of the complex interactions at play. Ultimately it may be most prudent to accept that sexuality and violence are related in a manner that is much more elaborate than any linear relationship we can measure and proceed methodologically with an investigation that is framed on a comprehensive structural model. 


\section{APPENDIX A}

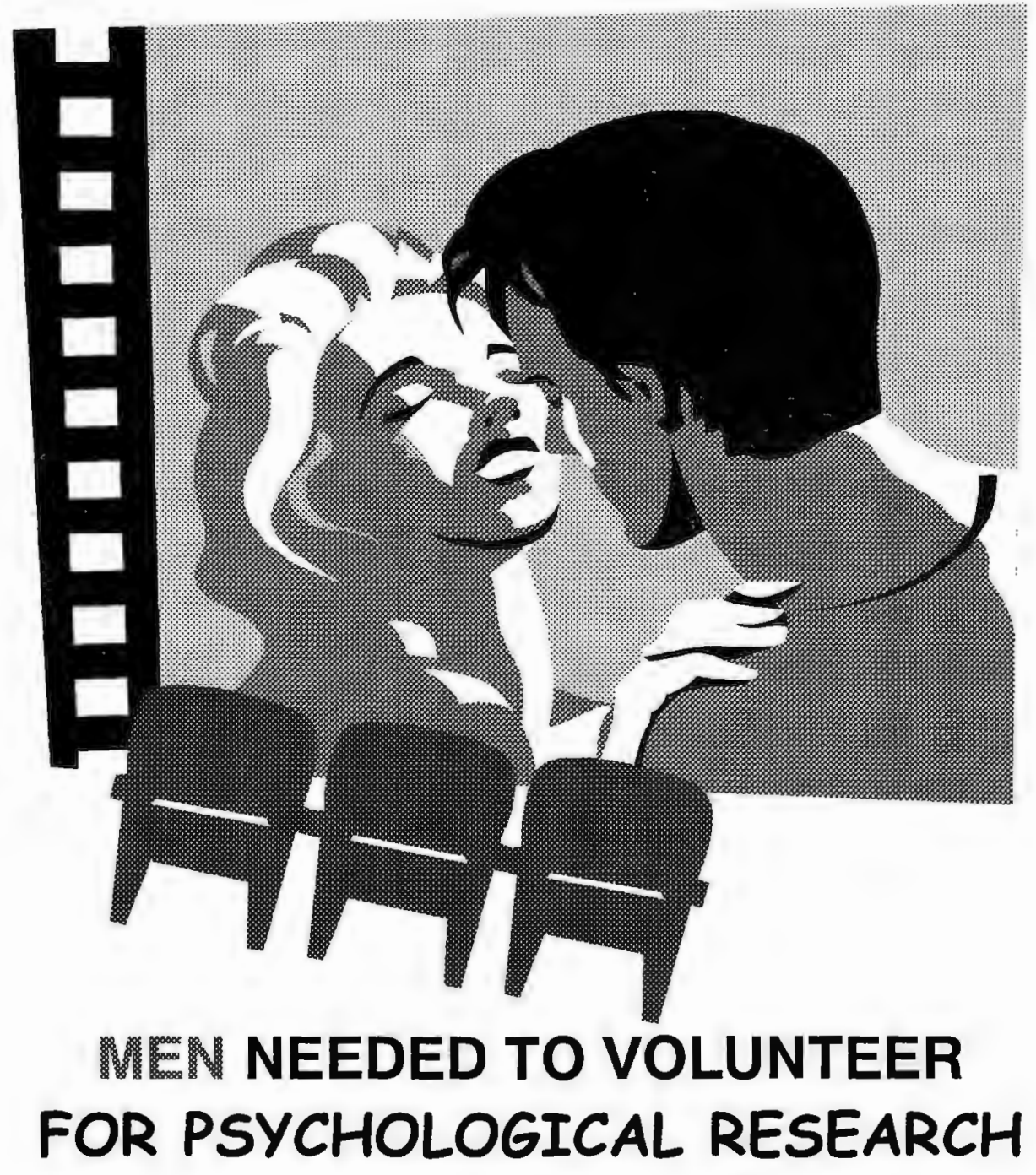

\section{A STUDY OF CONFLICT, SEX, AND PORNOGRAPHY \& PHYSIOLOGICAL AND SUBJECTIVE REACTIONS TO VIDEOTAPES}

Participation is strictly confidential and private. All interested males should sign up for an available time on the bulletin board across from Room 308 Chafee, remove the corresponding appointment card, and be at Room 159 Chafee at the appointed date and time for an individual session. The process should take approximately one hour. 


\section{APPENDIX A (continued)}

TEAR OFF ONE OF THESE REMINDERS

You have an appointment for a Psychological Study Monday, December $7^{\text {th }}$ at 12:30 $\mathrm{pm}$

in Chafee room 159 (enter the tunnel from the parking lot, turn left and follow the signs to room 159)

You have an appointment for a Psychological Study Monday, December $7^{\text {th }}$ at 2:00 pm

in Chafee room 159 (enter the tunnel from the parking lot, turn left and follow the signs to room 159)

You have an appointment for a Psychological Study Monday, December $7^{\text {th }}$ at 3:30 pm

in Chafee room 159 (enter the tunnel from the parking lot, turn left and follow the signs to room 159)

You have an appointment for a Psychological Study Monday, December $7^{\text {th }}$ at 5:00 pm

in Chafee room 159 (enter the tunnel from the parking lot, turn left and follow the signs to room 159)

You have an appointment for a Psychological Study Monday, December $7^{\text {th }}$ at $6: 30 \mathrm{pm}$

in Chafee room 159 (enter the tunnel from the parking lot, turn left and follow the signs to room 159)

You have an appointment for a Psychological Study Tuesday, December $8^{\text {th }}$ at 9:30 am

in Chafee room 159 (enter the tunnel from the parking lot, turn left and follow the signs to room 159)

You have an appointment for a Psychological Study

Tuesday, December $8^{\text {th }}$ at 11:00 am

in Chafee room 159 (enter the tunnel from the

parking lot, turn left and follow the signs to room 159)

You have an appointment for a Psychological Study

Tuesday, December $8^{\text {th }}$ at $12: 30$ pm

in Chafee room 159 (enter the tunnel from the

parking lot, turn left and follow the signs to room 159)

You have an appointment for a Psychological Study

Tuesday, December $8^{\text {th }}$ at 2:00 $\mathrm{pm}$

in Chafee room 159 (enter the tunnel from the

parking lot, turn left and follow the signs to room 159)

You have an appointment for a Psychological Study

Tuesday, December $8^{\text {th }}$ at 3:30 $\mathrm{pm}$

in Chafee room 159 (enter the tunnel from the

parking lot, turn left and follow the signs to room 159)

You have an appointment for a Psychological Study

Tuesday, December $8^{\text {th }}$ at $5: 00 \mathrm{pm}$

in Chafee room 159 (enter the tunnel from the

parking lot, turn left and follow the signs to room 159)
SIGN HERE
Monday, December $7^{\text {th }}$ at 2:00 pm

Monday, December $7^{\text {th }}$ at $3: 30 \mathrm{pm}$

Monday, December $7^{\text {th }}$ at $5: 00 \mathrm{pm}$

Monday, December $7^{\text {th }}$ at $6: 30 \mathrm{pm}$

Tuesday, December $8^{\text {"n }}$ at 9:30 am

Tuesday, December $8^{\text {th }}$ at 11:00 am

Tuesday, December $8^{\text {th }}$ at 12:30 pm

Tuesday, December $8^{\text {th }}$ at $2: 00 \mathrm{pm}$

Tuesday, December $8^{\text {th }}$ at 3:30 pm 


\section{APPENDIX B}

\section{LIFE EXPERIENCES AND SEXUALITY SURVEY}

Instructions: This survey contains a number of questions about you and your life experiences. Your help with this project is greatly appreciated. Be sure you answer every item. Put a check mark $\checkmark$ in the box next to your answer. If you aren't sure about an item, select the answer that seems about right.

1. What is your age? IF YOU ARE LESS THAN EIGHTEEN YEARS OLD, PLEASE TURN IN YOUR SURVEY NOW AND DO NOT CONTINUE.

2. What is your sexual orientation?
$\mathrm{a} \square$ exclusively heterosexual
$\mathrm{d} \square$ mostly homosexual
$\mathrm{b} \square$ mostly heterosexual
e $\square$ exclusively homosexual
$c \square$ bisexual

3. How long has your current intimate relationship (steady girlfriend) lasted?

(if not currently involved, your last previous relationship)?
$\mathrm{a} \square$ less than 1 month
$b \square$ from 1 to 6 months
$c \square$ from 6 months to a year
$\mathrm{d} \square$ more than a year
$\mathrm{e} \square$ never had an intimate relationship

4. Your frequency of sexual intercourse is...

$\mathrm{a} \square$ never $\mathrm{b} \square$ occasionally $\mathrm{c} \square$ once a month $\mathrm{d} \square$ weekly $\quad \mathrm{e} \square$ at least once daily

5. Number of sexual partners you have ever had...

$\mathrm{a} \square$ none $\mathrm{b} \square$ one $\mathrm{c} \square$ two to four $\mathrm{d} \square$ five to nine $\mathrm{e} \square$ ten or more

6. Currently a member of or rushing a fraternity?

$\mathrm{a} \square$ never rushed, pledged, or belonged

$b \square$ rushed/not pledged

$\mathrm{c} \square$ pledged/not yet active

$\mathrm{d} \square$ active member

7. Athletic involvement?
$\mathrm{a} \square$ do not participate at any level
$b \square$ participate informally, no regular team play
$\mathrm{c} \square$ participate in club sports
$\mathrm{d} \square$ participate in varsity sports, not basketball or football
$\mathrm{e} \square$ participate in varsity basketball or football

8. Favorite film..

9. Watch MTV or similar music television programming...

$a \square$ never $\quad b \square$ occasionally $c \square$ once a month $d \square$ weekly $\quad \mathrm{e} \square$ daily

10. During your last year in high school, were your parents...

$\mathrm{a} \square$ married \& living together $\mathrm{b} \square$ separated $\mathrm{c} \square$ divorced $\mathrm{d} \square$ widowed

$\mathrm{e} \square$ other (please explain)

11. During your last year in high school, with which parent(s) did you mostly live?

$\mathrm{a} \square$ mother \& father $\mathrm{b} \square$ mother only $\quad \mathrm{c} \square$ father only

$\mathrm{d} \square$ mother \& partner $\quad \mathrm{e} \square$ father \& partner

$\mathrm{f} \square$ other (please explain) 


\section{APPENDIX B (continued)}

No matter how well a couple gets along, there are times when they disagree, get annoyed with the other person, or just have spats or fights because they're in a bad mood or tired or for some other reason. They also use many different ways of trying to settle their differences.

The list below contains some things that your parents or your mother or father or other caretaker and the person they lived with or dated most often might have done when they had an argument. When they had an argument, how often did one or the other or both...

12. discuss an issue calmly?

$\mathrm{a} \square$ never $\mathrm{b} \square$ rarely $\mathrm{c} \square$ sometimes $\mathrm{d} \square$ frequently $\mathrm{e} \square$ always

13. get information to back up their side of things?

$a \square$ never $b \square$ rarely $c \square$ sometimes $d \square$ frequently $e \square$ always

14. bring someone in or tried to bring someone in to try to help settle things?

$\mathrm{a} \square$ never $\mathrm{b} \square$ rarely $\mathrm{c} \square$ sometimes $\mathrm{d} \square$ frequently $\mathrm{e} \square$ always

15. insult or swear at the other?

$\mathrm{a} \square$ never $\mathrm{b} \square$ rarely $\mathrm{c} \square$ sometimes $\mathrm{d} \square$ frequently $\quad \mathrm{e} \square$ always

16. sulk, refuse to talk?

$a \square$ never $b \square$ rarely $c \square$ sometimes $d \square$ frequently $\quad$ e $\square$ always

17. stomp out of the room or house or yard?

$\mathrm{a} \square$ never $\mathrm{b} \square$ rarely $\mathrm{c} \square$ sometimes $\mathrm{d} \square$ frequently $\mathrm{e} \square$ always

18. cry?

$\mathrm{a} \square$ never $\quad \mathrm{b} \square$ rarely $\mathrm{c} \square$ sometimes $\mathrm{d} \square$ frequently $\mathrm{e} \square$ always

19. did or said something to spite the other?

$\mathrm{a} \square$ never $\mathrm{b} \square$ rarely $\mathrm{c} \square$ sometimes $\mathrm{d} \square$ frequently $\mathrm{e} \square$ always

20. threatened to hit the other?

$\mathrm{a} \square$ never $\mathrm{b} \square$ rarely $\mathrm{c} \square$ sometimes $\mathrm{d} \square$ frequently $\mathrm{e} \square$ always

21. throw or smash something (but not at the other)?

$\mathrm{a} \square$ never $\mathrm{b} \square$ rarely $\mathrm{c} \square$ sometimes $\mathrm{d} \square$ frequently $\mathrm{e} \square$ always

22. throw something at the other?

$\mathrm{a} \square$ never $\mathrm{b} \square$ rarely $\mathrm{c} \square$ sometimes $\mathrm{d} \square$ frequently $\mathrm{e} \square$ always

23. push, grab, or shove the other?

$a \square$ never $b \square$ rarely $c \square$ sometimes $d \square$ frequently $\quad \mathrm{a}$ always

24. slap the other?

$\mathrm{a} \square$ never $\quad b \square$ rarely $\mathrm{c} \square$ sometimes $\mathrm{d} \square$ frequently $\quad \mathrm{e} \square$ always

25. kick, bite, or hit the other with a fist?

$\mathrm{a} \square$ never $\mathrm{b} \square$ rarely $\mathrm{c} \square$ sometimes $\mathrm{d} \square$ frequently $\mathrm{e} \square$ always 


\section{APPENDIX B (continued)}

26. hit or try to hit the other with something?

$a \square$ never $b \square$ rarely $c \square$ sometimes $d \square$ frequently $\quad \mathrm{e} \square$ always

27. beat the other up?

$\mathrm{a} \square$ never $\mathrm{b} \square$ rarely $\mathrm{c} \square$ sometimes $\mathrm{d} \square$ frequently $\mathrm{e} \square$ always

28. choke the other?

$a \square$ never $b \square$ rarely $c \square$ sometimes $d \square$ frequently $e \square$ always

29. threaten the other with a knife or gun?

$\mathrm{a} \square$ never $\mathrm{b} \square$ rarely $\mathrm{c} \square$ sometimes $\mathrm{d} \square$ frequently $\mathrm{e} \square$ always

30. used a knife or fired a gun?

$\mathrm{a} \square$ never $\mathrm{b} \square$ rarely $\mathrm{c} \square$ sometimes $\mathrm{d} \square$ frequently $\mathrm{e} \square$ always

In your own current intimate relationship (or last previous one), no matter how well you get along as a couple, there are times when you may disagree, get annoyed with your partner, or just have spats or fights because you're in a bad mood or tired or for some other reason. You also may use many different ways of trying to settle your differences.

The list below contains some things that you, yourself might have done when you had an argument. During this past year, when you had an argument with your partner (if you had no relationship in the past year, try to imagine how you would have acted), how often did you, yourself...

31. discuss an issue calmly?

$\mathrm{a} \square$ never $\mathrm{b} \square$ rarely $\mathrm{c} \square$ sometimes $\mathrm{d} \square$ frequently $\mathrm{e} \square$ always

32. get information to back up your side of things?

$\mathrm{a} \square$ never $\mathrm{b} \square$ rarely $\mathrm{c} \square$ sometimes $\mathrm{d} \square$ frequently $\mathrm{e} \square$ always

33. bring someone in or tried to bring someone in to try to help settle things?

$\mathrm{a} \square$ never $\mathrm{b} \square$ rarely $\mathrm{c} \square$ sometimes $\mathrm{d} \square$ frequently $\mathrm{e} \square$ always

34. insult or swear at your partner?

$\mathrm{a} \square$ never $\mathrm{b} \square$ rarely $\mathrm{c} \square$ sometimes $\mathrm{d} \square$ frequently $\mathrm{e} \square$ always

35. sulk, refuse to talk?

$\mathrm{a} \square$ never $\mathrm{b} \square$ rarely $\mathrm{c} \square$ sometimes $\mathrm{d} \square$ frequently $\mathrm{e} \square$ always

36. stomp out of the room or house or yard?

$\mathrm{a} \square$ never $\mathrm{b} \square$ rarely $\mathrm{c} \square$ sometimes $\mathrm{d} \square$ frequently $\mathrm{e} \square$ always

37. cry?

$a \square$ never $b \square$ rarely $c \square$ sometimes $d \square$ frequently $\quad \mathrm{e} \square$ always

38. did or said something to spite your partner?

$\mathrm{a} \square$ never $\mathrm{b} \square$ rarely $\mathrm{c} \square$ sometimes $\mathrm{d} \square$ frequently $\mathrm{e} \square$ always

39. threatened to hit your partner?

$\mathrm{a} \square$ never $\mathrm{b} \square$ rarely $\mathrm{c} \square$ sometimes $\mathrm{d} \square$ frequently $\mathrm{e} \square$ always 


\section{APPENDIX B (continued)}

40. throw or smash something (but not at your partner)?

$\mathrm{a} \square$ never $\mathrm{b} \square$ rarely $\mathrm{c} \square$ sometimes $\mathrm{d} \square$ frequently $\mathrm{e} \square$ always

41. throw something at your partner?

$\mathrm{a} \square$ never $\mathrm{b} \square$ rarely $\mathrm{c} \square$ sometimes $\mathrm{d} \square$ frequently $\mathrm{e} \square$ always

42. push, grab, or shove your partner?

$\mathrm{a} \square$ never $\mathrm{b} \square$ rarely $\mathrm{c} \square$ sometimes $\mathrm{d} \square$ frequently $\mathrm{e} \square$ always

43. slap your partner?

$a \square$ never $b \square$ rarely $c \square$ sometimes $d \square$ frequently $\quad$ e $\square$ always

44. kick, bite, or hit your partner with your fist?

$\mathrm{a} \square$ never $\mathrm{b} \square$ rarely $\mathrm{c} \square$ sometimes $\mathrm{d} \square$ frequently $\mathrm{e} \square$ always

45. hit or try to hit your partner with something?

$\mathrm{a} \square$ never $\mathrm{b} \square$ rarely $\mathrm{c} \square$ sometimes $\mathrm{d} \square$ frequently $\mathrm{e} \square$ always

46. beat your partner up?

$\mathrm{a} \square$ never $\mathrm{b} \square$ rarely $\mathrm{c} \square$ sometimes $\mathrm{d} \square$ frequently $\mathrm{e} \square$ always

47. choke your partner?

$\mathrm{a} \square$ never $\mathrm{b} \square$ rarely $\mathrm{c} \square$ sometimes $\mathrm{d} \square$ frequently $\mathrm{e} \square$ always

48. threaten your partner with a knife or gun?

$\mathrm{a} \square$ never $\mathrm{b} \square$ rarely $\mathrm{c} \square$ sometimes $\mathrm{d} \square$ frequently $\mathrm{e} \square$ always

49. used a knife or fired a gun?

$a \square$ never $b \square$ rarely $c \square$ sometimes $d \square$ frequently $\quad \mathrm{e} \square$ always

Please check $\checkmark$ YES or NO to the following questions:

50. DYES $\square$ NO Has a woman given in to sex play with you (fondling, kissing, or petting, but not intercourse) when she didn't want to because she was overwhelmed by your continual arguments and pressure?

51. $\square Y E S$ DNO Have you had sex play with a woman (fondling, kissing, or petting, but not intercourse) when she didn't want to because you used your position of authority (boss, teacher, camp counselor, supervisor) to make her?

52. $\square$ YES $\square$ NO Have you had sex play with a woman (fondling, kissing, or petting, but not intercourse) when she didn't want to because you threatened or used some degree of physical force (twisting her arm, holding her down, etc.) to make her?

53. $\square$ YES $\square$ NO Have you ever attempted sexual intercourse with a woman (get on top of her, attempt to insert your penis) when she didn't want to by threatening or using some degree of force (twisting her arm, holding her down, etc.) but intercourse did not occur?

54. $\square$ YES $\square$ NO Have you ever attempted sexual intercourse with a woman (get on top of her, attempt to insert your penis) when she didn't want to by giving her alcohol or drugs, but intercourse did not occur? 


\section{APPENDIX B (continued)}

55. $\square$ YES $\square$ NO Has a woman given in to sexual intercourse with you when she didn't want to because she was overwhelmed by your continual arguments and pressure?

56. $\square$ YES $\square$ NO Has a woman had sexual intercourse with you when she didn't want to because you used your position of authority (boss, teacher, camp counselor, supervisor) to make her?

57. $\square$ YES $\square$ NO Has a woman had sexual intercourse with you when she didn't want to because you gave her alcohol or drugs?

58. $\square$ YES $\square$ NO Has a woman had sexual intercourse with you when she didn't want to because you threatened or used some degree of physical force (twisting her arm, holding her down, etc.) to make her?

59. $\square$ YES $\square$ NO Have you had sex acts with a woman (anal or oral intercourse or penetration by objects other than your penis) when she didn't want to because you threatened or used some degree of physical force (twisting her arm, holding her down, etc.) to make her?

Please indicate whether or not you have ever experienced the following by checking YES or NO for each item. Please answer honestly and do not skip any items.

60. $\square$ YES $\square$ NO Your nude breast felt by partner

61. $\square$ YES $\square$ NO Partner mouth contact with your breast

62. $\square$ YES $\square$ NO Penetration of your partner's vagina by your finger

63. $\square$ YES $\square$ NO Lying on top of your partner without penetration

64. $\square$ YES $\square$ NO Partner's observation of your nude body

65. $\square$ YES $\square$ NO Clitoral manipulation of partner

66. $\square$ YES $\square$ NO Your observation of nude partner

67. $\square$ YES $\square$ NO Partner manipulation of your genitals

68. $\square$ YES $\square$ NO Partner's manipulation of your penis

69. $\square$ YES $\square$ NO Sexual intercourse, male superior ("on top")

70. $\square$ YES $\square$ NO Your partner's mouth in contact with your penis

71. $\square$ YES $\square$ NO Your mouth in contact with your partner's external genitals

72. $\square$ YES $\square$ NO Your tongue manipulating your partner's clitoris

73. $\square$ YES $\square$ NO Your tongue penetrating your partner's vagina

74. $\square$ YES $\square$ NO Sexual intercourse, face to face, lying on sides

75. $\square$ YES $\square$ NO Showering or bathing with partner 


\section{APPENDIX B (continued)}

76. $\square$ YES $\square$ NO Exposure to erotic materials shown openly in newsstands

77. $\square$ YES $\square$ NO Sexual intercourse, partially clothed

78. $\square$ YES $\square$ NO Clitoral manipulation of partner until she reaches orgasm

79. $\square Y E S$ DNO Sexual intercourse, female superior ("on top")

80. $\square$ YES $\square$ NO Masturbation (touching yourself for sexual pleasure)

81. $\square$ YES $\square$ NO Sexual intercourse, entering vagina from rear (your front to partner's back)

82. $\square$ YES $\square$ NO Mutual oral stimulation of genitals to orgasm

83. $\square Y E S \square N O$ Partner's tongue stimulating your genitals until you reach orgasm

84. $\square$ YES $\square$ NO Your hand touching partner's anal area

85. DYES INO Sexual intercourse, sitting position

86. $\square$ YES $\square$ NO Sexual intercourse, standing

87. $\square$ YES $\square$ NO Exposure to hardcore erotic materials

88. $\square$ YES $\square$ NO Your finger penetrates partner's anus

89. $\square$ YES $\square$ NO Anal intercourse

Check $\checkmark$ the answer that represents, in the last year, how often you have used sexually explicit or pornographic materials (e.g., books, magazines, films, videotapes) that depicted...

90. Group sex

$\mathrm{a} \square$ never $\mathrm{b} \square$ occasionally $\mathrm{c} \square$ once a month $\mathrm{d} \square$ weekly $\mathrm{e} \square$ daily

91. Female homosexual acts

$\mathrm{a} \square$ never $\quad \mathrm{b} \square$ occasionally $\mathrm{c} \square$ once a month $\mathrm{d} \square$ weekly $\mathrm{e} \square$ daily

92. Whipping, spanking, or beating of women

$\mathrm{a} \square$ never $\mathrm{b} \square$ occasionally $\mathrm{c} \square$ once a month $\mathrm{d} \square$ weekly $\mathrm{e} \square$ daily

93. A man forcing a woman to perform a sexual act against her will

$\mathrm{a} \square$ never $\mathrm{b} \square$ occasionally $\mathrm{c} \square$ once a month $\mathrm{d} \square$ weekly $\mathrm{e} \square$ daily

94. Sexual acts with animals

$\mathrm{a} \square$ never $\mathrm{b} \square$ occasionally $\mathrm{c} \square$ once a month $\mathrm{d} \square$ weekly $\mathrm{e} \square$ daily

95. Rape of a woman (or women) by a man (or many men)

$\mathrm{a} \square$ never $\mathrm{b} \square$ occasionally $\mathrm{c} \square$ once a month $\mathrm{d} \square$ weekly $\mathrm{e} \square$ daily

96. Bondage of women

$\mathrm{a} \square$ never $\mathrm{b} \square$ occasionally $\mathrm{c} \square$ once a month $\mathrm{d} \square$ weekly $\mathrm{e} \square$ daily 


\section{APPENDIX B (continued)}

97. Male homosexual acts

$\mathrm{a} \square$ never $\mathrm{b} \square$ occasionally $\mathrm{c} \square$ once a month $\mathrm{d} \square$ weekly $\mathrm{e} \square$ daily

98. Torture or mutilation of women

$\mathrm{a} \square$ never $\mathrm{b} \square$ occasionally $\mathrm{c} \square$ once a month $\mathrm{d} \square$ weekly $\mathrm{e} \square$ daily

99. Masturbation

$\mathrm{a} \square$ never $b \square$ occasionally $\mathrm{c} \square$ once a month $\mathrm{d} \square$ weekly $\mathrm{e} \square$ daily

100. Mutually consenting sex between a man and a woman

(not involving any of the above themes)

$\mathrm{a} \square$ never $\mathrm{b} \square$ occasionally $\mathrm{c} \square$ once a month $\mathrm{d} \square$ weekly $\mathrm{e} \square$ daily 


\title{
APPENDIX C
}

\author{
The University of Rhode Island Department of Psychology \\ Kingston, RI 02881-0808 \\ A Study of Conflict Tactics, Sex Experience, Sexual Behavior, and Pornography
}

\section{CONSENT FORM FOR RESEARCH}

I have been asked to take part in a research project described below. The researcher will explain the project to me in detail. I should feel free to ask questions. If I have more questions later, James Miller, the person mainly responsible for the study, (401)874-2726, will discuss them with me. I understand that 1 must be at least 18 years old to be in this research project.

\section{Description of the project:}

I have been asked to take part in a study of conflict tactics, sex experience, sexual behavior, and pornography. The purpose of the study is to provide information which may contribute to the theoretical understanding of associations between one's past history and current behavior.

\section{What will be done:}

If I decide to take part in this study, here is what will happen: I will be asked to answer a series of questions about conflict tactics, sex experience, sexual behavior, and pornography. This survey will take about 45 minutes to complete.

\section{Risks or discomforts:}

I may feel uncomfortable about answering personal questions. If at any time I do not wish to continue, I am free to stop, without any undue consequences.

\section{Benefits of the study:}

Although there may be no direct benefit to me for taking part in this study, other than having had the experience of participating in a formal study, my participation will greatly assist the researcher in learning more about conflict tactics, sex experience, sexual behavior, and pornography. He will gladly discuss the findings with me now, or at any time in the future. If I would like to receive an abstract of the final results, I can provide the researcher with my name and permanent address, and it will be mailed to me after all data are collected and analyzed.

\section{Confidentiality:}

My participation in the study is anonymous and confidential. None of the information will identify me by name. All records will be identified by a numerical code alone. Consent forms and requests for an abstract of the final results, which contain identifying information, will not contain the code number and will be filed separately from the coded data sheets so that the investigator will not be able to link me with my responses. Forms will be stored in a locked file cabinet within a locked laboratory.

\section{Decision to quit at any time:}

The decision whether or not to take part in this study is up to me. I do not have to participate. If I decide to take part in this study, I may quit at any time. Whatever I decide will in no way affect my grade or otherwise impact on my status as a student or as a member of the university community. If I wish to quit during the experiment I can simply leave the room and inform the researcher of my decision. He will then be available to deal with any questions or concerns I might have. 


\section{APPENDIX C (continued)}

In case there is harm to the participant:

Participants who feel that they are harmed as a result of this study may contact Dr. Pauline Wood at University Health Services (telephone: $874-4757$ ), Dr. Jim Campbell at the University Counseling Center (telephone: 874-2288), or their private health care provider. If this study causes me any harm, I should write or call the University of Rhode Island's Vice Provost of Research, 70 Lower College Road, University of Rhode Island, Kingston, RI 02881 (telephone: 874-2635).

Rights and complaints:

If I am not satisfied with the way this study is performed, I may discuss my complaints with James Miller or with Dr. Patricia J. Morokoff (telephone: 874-4239), anonymously, if I choose.

I have read the Consent Form. My questions have been answered. My signature on this form means that I understand the information, I agree to participate in this study, and I certify that I am at least 18 years old.

Signature of Participant

$\overline{\text { Signature of Researcher }}$

Typed/printed name

Typed/printed name

Date

Date 


\title{
APPENDIX D
}

\author{
The University of Rhode Island Department of Psychology \\ Kingston, RI 02881-0808 \\ A Study of Reactions to Erotic, Rape, and Violent Videotapes
}

\section{CONSENT FORM FOR RESEARCH}

I have been asked to take part in a research project described below. The researcher will explain the project to me in detail. I should feel free to ask questions. If I have more questions later, James Miller, the person mainly responsible for the study, (401)874-2726, will discuss them with me.

\section{Description of the project:}

I have been asked to take part in a study of reactions to erotic, rape, and violent videotapes. The purpose of the study is to provide information which may contribute to the theoretical understanding of physiological and subjective reactions to watching sexually explicit or violent videotapes. I understand that I must be at least 18 years old to be in this research project.

\section{What will be done:}

If I decide to take part in this study, here is what will happen: I will be asked to sit in a private room where a blood pressure cuff will be attached to my left upper arm and then in private, behind a locked door, I will attach a comfortable elastic band about half way up the shaft of my penis. I will then watch four 5-minute videotapes which will depict explicit sexual and violent activity. While I watch each videotape I will be asked to indicate the level of sexual arousal which I experience by moving a lever. During this time any questions will be answered via intercom. At the completion of the experiment, I will remove the elastic band, unlock the door when I am ready, and the researcher, who is a doctoral candidate in experimental psychology, will answer any further questions and discuss any concerns or feedback I might have about my participation in the study. This session will take about 60 minutes to complete.

\section{Risks or discomforts:}

I may feel uncomfortable about attaching or removing the elastic band and/or viewing the sexually explicit or violent videotapes. I may feel discomfort during inflation of the blood pressure cuff. The elastic band is disinfected according to a standardized procedure which has been extensively researched by the manufacturer of the disinfectant, who reports virtually no possibility of health hazard exists. It is thus believed there is no risk to your health, but a remote possibility always exists. In some cases, emotional discomfort may persist for a while after my participation in the study is completed. However, this is not a common occurrence in studies of this type. If at any time I do not wish to continue, I am free to stop, without any undue consequences.

\section{Benefits of the study:}

Although there may be no direct benefit to me for taking part in this study, other than having had the experience of participating in a formal study, my participation will greatly assist the researcher in learning more about physiological and subjective reactions to watching sexually explicit or violent videotapes. He will gladly discuss the findings with me now, or at any time in the future. If I would like to receive an abstract of the final results, I can provide the researcher with my name and permanent address, and it will be mailed to me after all data are collected and analyzed. 


\section{APPENDIX D (continued)}

Confidentiality:

My participation in the study is anonymous and confidential. None of the information will identify me by name. All records will be identified by a numerical code alone. Consent forms and requests for an abstract of the final results, which contain identifying information, will not contain the code number and will be filed separately from the coded data sheets so that the investigator will not be able to link me with my responses. Forms will be stored in a locked file cabinet within a locked laboratory.

Decision to quit at any time:

The decision whether or not to take part in this study is up to me. I do not have to participate. If I decide to take part in this study, I may quit at any time. Whatever I decide will in no way affect my grade or otherwise impact on my status as a student or as a member of the university community. If I wish to quit during the experiment I can simply leave the room and inform the researcher of my decision. He will then be available to deal with any questions or concerns I might have.

In case there is harm to the participant:

Participants who feel that they are harmed as a result of this study may contact Dr. Pauline Wood at University Health Services (telephone: 874-4757), Dr. Jim Campbell at the University Counseling Center (telephone: 874-2288), or their private health care provider. If this study causes me any harm, I should write or call the University of Rhode Island's Vice Provost of Research, 70 Lower College Road, University of Rhode Island, Kingston, RI 02881 (telephone: 874-2635).

Rights and complaints:

If I am not satisfied with the way this study is performed, I may discuss my complaints with James Miller or with Dr. Patricia J. Morokoff (telephone: 874-4239), anonymously, if I choose.

I have read the Consent Form. My questions have been answered. My signature on this form means that I understand the information, I agree to participate in this study, and I certify that I am at least 18 years old.

$\overline{\text { Signature of Participant }}$

Typed/printed name
Signature of Researcher

Typed/printed name

Date

Date 


\section{APPENDIX E}

\section{EXIT / DEBRIEFING INFORMATION}

This was a study about physiological and subjective reactions to watching sexually explicit or violent videotapes. While it was probably obvious to you, 1 would like to emphasize that the excerpts you saw on videotape were COMPLETE FANTASY. These depictions of rape and violence were dramatizations. In reality, as you are hopefully aware, rape and battering are terrible crimes and are punishable by prison sentences. In addition, rape and assault victims suffer severe psychological damage as well as the more obvious physical effects of the assault.

Unfortunately, many people still believe a number of false ideas or myths about rape. For example, one totally unfounded myth is that if a woman does not immediately report a rape or hesitates to report it, then the act is somehow not considered a real rape. A second falsehood is that if a woman does anything which puts her at greater risk or makes her more vulnerable to being victimized (e.g., going to a man's apartment, wearing enticing clothing, etc.) she somehow brings the rape upon herself. These are in fact just myths and are totally unfounded. Hopefully, you will leave this experiment with a more realistic and accurate view of rape.

(after Malamuth \& Check, 1984) 


\section{BIBLIOGRAPHY}

Allen, M., D'Alessio, D., Emmers, T. M., \& Gebhardt, L. (1996). The role of educational briefings in mitigating effects of experimental exposure to violent sexually explicit materials: A meta-analysis. The Journal of Sex Research, 33, 135-141.

Bandura, A. (1977). Social Learning Theory. Englewood Cliffs, NJ: Prentice-Hall.

Bandura, A., Ross, D., \& Ross, S. (1963). A comparative test of the status envy, social power, and secondary reinforcement theories of identificatory learning. Journal of Abnormal and Social Psychology, 67, 527-534.

Barlow, D. H. (1986). Causes of sexual dysfunction: The role of anxiety and cognitive interference. Journal of Consulting and Clinical Psychology, 54, 140-157.

Barlow, D. H., Sakheim, D. K., \& Beck, J. G. (1983). Anxiety increases sexual arousal. Journal of Abnormal Psychology, 92, 49-54.

Barongan, C., \& Hall, G. C. N. (1995). The influence of misogynous rap music on sexual aggression against women. Psychology of Women Quarterly, 19, 195-207.

Bentler, P. M. (1968a). Heterosexual behavior assessment - I. Males. Behaviour Research and Therapy, 6, 21-25.

Bentler, P. M. (1968b). Heterosexual behavior assessment - Il. Females. Behaviour Research and Therapy, 6, 27-30. 
Berkowitz, L. (1986). Situational influences on reactions to observed violence. Journal of Social Issues, 42, 93-106.

Berkowitz, L. (1993). Aggression: Its Causes, Consequences, and Control. Philadelphia: Temple University Press.

Briere, J., \& Malamuth, N. (1983). Self-reported likelihood of sexually aggressive behavior: Attitudinal vs. sexual explanations. Journal of Research in Personality, 17, 315-323.

Brownmiller, S. (1975). Against our will: Men, women, and rape. New York: Simon \& Schuster.

Byrne, D. (1986). The study of sexual behavior as a multidisciplinary venture. In D. Byrne \& K. Kelley (Eds.), Alternative approaches to the study of sexual behavior (pp. 1-12). Hillsdale, NJ: Erlbaum.

Carlson, B. E. (1984). Children's observations of interparental violence. In A. R. Roberts (Ed.), Battered women and their families: Intervention strategies and treatment programs (pp. 147-167). New York: Springer.

Carrado, M., George, M. J., Loxam, E., Jones, L., \& Templar, D. (1996). Aggression in British heterosexual relationships: A descriptive analysis. Aggressive Behavior, 22, 401-415.

Ceniti, J., \& Malamuth, N. M. (1984). Effects of repeated exposure to sexually violent or nonviolent stimuli on sexual arousal to rape and nonrape depictions. Behavioural Research and Therapy, 22, 535-548. 
Christopher, F. S., Madura, M, \& Weaver, L. (1998). Premarital sexual aggressors: A multivariate analysis of social, relational, and individual variables. Journal of Marriage and the Family, 60, 56-69.

Christopoulos, C., Cohn, D., Shaw, D., Joyce, S., Sullivan-Hanson, J., Kraft, S., \& Emery, R. (1987). Children of abused women: I. Adjustment at time of shelter residence. Journal of Marriage and the Family, 49, 611-619.

Cohen, J. (1988). Statistical power analysis for the behavioral sciences, Second edition. Hillsdale, NJ: Lawrence Erlbaum Associates.

Cowart, D. A., \& Pollack, R. H. (1979). A Guttman scale of sexual experience. Journal of Sex Education and Therapy, 1, 3-6.

Cowart-Steckler, D. (1984). A Guttman scale of sexual experience: An update. Journal of Sex Education \& Therapy, 10, 49-50.

Cowart-Steckler, D., \& Pollack, R. H. (1988). The Cowart-Pollack Scale of Sexual Experience. In C. M. Davis, W. L. Yarber, \& S. L. Davis (Eds.), Sexualityrelated measures: A compendium. Lake Mills, lowa: Graphic Publishing Company.

Craig, M. E., Kalichman, S. C., \& Follingstad, D. R. (1989). Verbal coercive sexual behavior among college students. Archives of Sexual Behavior, $18,421-434$.

Cummings, E. M. (1998). Children exposed to marital conflict and violence: Conceptual and theoretical directions. In G. W. Holden, R. Geffner, \& E. N. Jouriles (Eds.), Children exposed to marital violence: Theory, research, 
and applied issues (pp. 55-93). Washington, DC: American Psychological Association.

Cummings, E. M., lannotti, R. J., \& Zahn-Waxler, C. (1985). Influence of conflict between adults on the emotions and aggression of young children. Developmental Psychology, 21, 495-507.

Day, D. M., Miner, M. H., Sturgeon, V. H., \& Murphy, J. (1989). Assessment of sexual arousal by means of physiological and self-report measures. In D. R. Laws (Ed.) Relapse prevention with sex offenders. (pp. 155123). New York: Guilford Press.

Demaré, D., Briere, J., \& Lips, H. M. (1988). Violent pornography and selfreported likelihood of sexual aggression. Journal of Research in Personality, 22, 140-153.

DeMaris, A. (1992). Male versus female initiation of aggression: The case of courtship violence. In E. C. Viano (Ed.) Intimate violence: Interdisciplinary perspectives. (pp. 111-120). New York: Hemisphere Publishing Corp.

Dutton, D. G., \& Aron, A. P. (1974). Some evidence for heightened sexual attraction under conditions of high anxiety. Journal of Personality and Social Psychology, 30, 510-517.

Earls, C. M., \& Marshal, W. L. (1983). The current state of technology in the laboratory: Assessment of sexual arousal patterns. In J. G. Greer, \& J. R. Stuart (Eds.), The sexual aggressor: Current perspectives on treatment. (pp. 336-362). New York: Van Nostrand Reinhold. 
Farrall, W. R., \& Card, R. D. (1988). Advancements in physiological evaluation of assessment and treatment of the sexual aggressor. In R. A. Prentky, \& V. L. Quinsey (Eds.), Human sexual aggression: Current perspectives (pp. 261-273). New York: New York Academy of Sciences.

El-Sheikh, M., \& Reiter, S. L. (1996). Children's responding to live interadult conflict: The role of form of anger expression. Journal of Abnormal Child Psychology, 24, 401-415.

Fantuzzo, J., DePaola, L., Lambert, L., Martino, T., Anderson, G., \& Sutton, S. (1991). Effects of interparental violence on the psychological adjustment and competencies of young children. Journal of Consulting and Clinical Psychology, 59, 258-265.

Fantuzzo, J. W., \& Lindquist, C. U. (1989). The effects of observing conjugal violence on children: A review and analysis of research methodology. Journal of Family Violence, 4, 77-93.

Farrall, W. R., \& Card, R. D. (1988). Advancements in physiological evaluation of assessment and treatment of the sexual aggressor. In R. A. Prentky, \& V. L. Quinsey (Eds.), Human sexual aggression: Current perspectives (pp. 261-273). New York: New York Academy of Sciences.

Fischer, G. J. (1992). Sex attitudes and prior victimization as predictors of college student sex offenses. Annals of Sex Research, 5, 53-60. ForsstromCohen, B., \& Rosenbaum, A. (1985). The effects of parental marital violence on young adults: An exploratory investigation. Journal of Marriage and the Family, $47,467-472$. 
Franklin, M. E., Morokoff, P. J., \& Calderone, K. L. (1991, August).

Undergraduate male sexual response to erotic, violent, and violent-erotic videotapes. Paper presented at the annual meeting of the American Psychological Association, San Francisco, CA.

Freud, S. (1909/1962). Three Essays on the Theory of Sexuality. (J. Strachey, Trans.). New York: Basic Books.

Geen, R. G. (1990). Human aggression. Pacific Grove, CA: Brooks/Cole.

Geer, J. H. (1976). Genital measures: Comments on their role in understanding human sexuality. Journal of Sex and Marital Therapy, 2, 165-172.

Goldstein, M. J., Kant, H. S., \& Hartmann, J. J. (1973). Pornography and Sexual Deviance. Los Angeles: University of California Press.

Hall, G. C, N., \& Barongan, C. (1997). Prevention of sexual aggression: Sociocultural risk and protective factors. American Psychologist, 52, 5-14.

Hall, G. C. N., \& Hirschman, R. (1991). Toward a theory of sexual aggression: A quadripartite model. Journal of Consulting and Clinical Psychology, 59, 662-669.

Hall, G. C. N., \& Hirschman, R. (1994). The relationship between men's sexual aggression inside and outside the laboratory. Journal of Consulting and Clinical Psychology, 62, 375-380.

Hall, G. C. N., Shondrick, D. D., \& Hirschman, R. (1993). The role of sexual arousal in sexually aggressive behavior: A meta-analysis. Journal of Consulting and Clinical Psychology, 61, 1091-1095. 
Heiman, J. R., \& Rowland, D. L. (1983). Affective and physiological sexual response patterns: The effects of instructions on sexually functional and dysfunctional men. Journal of Psychosomatic Research, 27, 105-116.

Henning, K., Leitenberg, H., Coffey, P., Bennett, T., \& Jankowski, M. K. (1997). Long-term psychological adjustment to witnessing interparental physical conflict during childhood. Child Abuse \& Neglect, 21, 501-515.

Henning, K., Leitenberg, H., Coffey, P., Turner, T., \& Bennett, R. (1996). Long-term psychological and social impact of witnessing physical conflict between parents. Journal of Interpersonal Violence, 11, 35-51.

Hoon, P. W., Wincze, J. P., \& Hoon, E. F. (1977). A test of reciprocal inhibition: Are anxiety and sexual arousal in women mutually inhibitory? Journal of Abnormal Psychology, 86, 65-74.

Hotaling, G. T., \& Sugarman, D. B. (1986). An analysis of risk markers in husband to wife violence: The current state of knowledge. Violence and Victims, $1,101-124$.

Hughes, H. M., Parkinson, D., \& Vargo, M. (1989). Witnessing spouse abuse and experiencing physical abuse: A "double whammy?" Journal of Family Violence, 4, 197-209.

Irwin, A. R., \& Gross, A. M. (1995). Cognitive tempo, violent video games, and aggressive behavior in young boys. Journal of Family Violence, 10, 337-350. Johnson, A. G. (1980). On the prevalence of rape in the United States. Signs: Journal of Women in Culture and Society, 6, 136-146. 
Jouriles, E. N., Barling, J., \& O'Leary, K. D. (1987). Predicting child behavior problems in maritally violent families. Journal of Abnormal Child Psychology, 15, 165-173.

Jouriles, E. N., Murphy, C. M., \& O’Leary, K. D. (1989). Interspousal aggression, marital discord, and child problems. Journal of Consulting and Clinical Psychology, 57, 453-455.

Jouriles, E. N., Norwood, W. D., McDonald, R., Vincent, J. P., \& Mahoney, A. (1996). Physical violence and other forms of marital aggression: Links with children's behavior problems. Journal of Family Psychology, 10, 223-234.

Kalmuss, D. (1984). The intergenerational transmission of marital aggression. Journal of Marriage and the Family, 46, 11-19.

Kanin, E. J. (1957). Male aggression in dating-courtship relations. American Journal of Sociology, 63, 197-204.

Kanin, E. J. (1983). Rape as a function of relative sexual frustration. Psychological Reports, 52, 133-134.

Kilpatrick, D. G., Best, C. L., Veronen, L. J., Amick, A. E., Villeponteaux, L. A., \& Ruff, G. A. (1985). Mental health correlates of criminal victimization: A random community survey. Journal of Consulting and Clinical Psychology, 53, 866-873.

Kolbo, J. R., Blakely, E. H., \& Engleman, D. (1996). Children who witness domestic violence: A review of empirical literature. Journal of Interpersonal Violence, 11, 281-293. 
Koss, M. P. (1993). Rape: Scope, impact, interventions, and public policy responses. American Psychologist, 48, 1062-1069.

Koss, M. P. (1993a). Detecting the scope of rape: A review of prevalence research methods. Journal of Interpersonal Violence, 8, 198-222.

Koss, M. P., \& Gaines, J. A. (1993). The prediction of sexual aggression by alcohol use, athletic participation, and fraternity affiliation. Journal of Interpersonal Violence, 8, 94-108.

Koss, M. P., \& Gidycz, C. A. (1985). Sexual experiences survey: Reliability and validity. Journal of Counseling and Clinical Psychology, 53, 422-423.

Koss, M. P.; Gidycz, C. A.; \& Wisniewski, N. (1987). The scope of rape: Incidence and prevalence of sexual aggression and victimization in a national sample of higher education students. Journal of Consulting and Clinical Psychology, 55, 162-170.

Koss, M. P., Heise, L., \& Russo, N. F. (1994). The global health burden of rape. Psychology of Women Quarterly, 18, 509-537.

Koss, M. P., Leonard, K. E., Beezley, D. A., \& Oros, C. J. (1985).

Nonstranger sexual aggression: A discriminant analysis of the psychological characteristics of undetected offenders. Sex Roles, 12, 981-992.

Koss, M. P., \& Oros, C. J. (1982). Sexual experiences survey: A research instrument investigating sexual aggression and victimization. Journal of Consulting and Clinical Psychology, 50, 455-457.

Lackie, L., \& de Man, A. F. (1997). Correlates of sexual aggression among male university students. Sex Roles, 37, 451-457. 
Langevin, R., Paitich, D., \& Russon, A. E. (1985). Are rapists sexually anomalous, aggressive or both? In R. Langevin (Ed.), Erotic preference, gender identity, and aggression in men: New research studies (pp. 17-38). Hillsdale, NJ: Erlbaum.

Laumakis, M. A., Margolin, G., \& John, R. S. (1998). The emotional, cognitive, and coping responses of preadolescent children to different dimensions of marital conflict. In G. W. Holden, R. Geffner, \& E. N. Jouriles (Eds.), Children exposed to marital violence: Theory, research, and applied issues (pp. 257-288). Washington, DC: American Psychological Association.

Malamuth, N. M. (1986). Predictors of naturalistic sexual aggression. Journal of Personality and Social Psychology, 50, 953-962.

Malamuth, N. (1994). Pornography's impact on male adolescents. The Amplifier, Fall, 1994, 3,10-11.

Malamuth, N. M., \& Briere, J. (1986). Sexual violence in the media: Indirect effects on aggression against women. Journal of Social Issues, 42, 7592.

Malamuth, N. M., \& Ceniti, J. (1986). Repeated exposure to violent and nonviolent pornography: Likelihood of raping ratings and laboratory aggression against women. Aggressive Behavior, 12, 129-137.

Malamuth, N. M., \& Check, J. V. P. (1983). Sexual arousal to rape depictions: Individual differences. Journal of Abnormal Psychology, 92, 55-67. 
Malamuth, N. M., \& Check, J. V. P. (1985). The effects of aggressive pornography on beliefs in rape myths: Individual differences. Journal of Research in Personality, 19, 299-320.

Malamuth, N. M., Check, J. V. P., \& Briere, J. (1986). Sexual arousal in response to aggression: Ideological, aggressive, and sexual correlates. Journal of Personality and Social Psychology, 50, 330-340.

McConaghy, N., \& Zamir, R. (1995). Heterosexual and homosexual coercion, sexual orientation and sexual roles in medical students. Archives of Sexual Behavior, 24, 489-502.

Mc Cord, J. (1986). Instigation and insulation: How families affect antisocial aggression. In D. Olweus, J. Block, \& M. Radke-Yarrow (Eds.), Development of antisocial and prosocial behavior: Research, theories, and issues. Orlando, FL: Academic Press, pp. 343-357.

Morokoff, P. J. (1981). Female sexual arousal as a function of individual differences and exposure to erotic stimuli. Dissertation Abstracts International, 41, 4270-B. (University Microfilms No. 8109039).

Morokoff, P. J. (1985). Effects of sex guilt, repression, sexual "arousability," and sex experience on female sexual arousal during erotica and fantasy. Journal of Personality and Social Psychology, 49, 177-187.

Mosher, D. L., \& Sirkin, M. (1984). Measuring a macho personality constellation. Journal of Research in Personality, 18, 150-163. 
Muehlenhard, C. L., \& Linton, M. A. (1987). Date rape and sexual aggression in dating situations: Incidence and risk factors. Journal of Counseling Psychology, 34, 186-196.

Nisbett, R. E., \& Schachter, S. (1966). Cognitive manipulation of pain. Journal of Experimental Social Psychology, 2, 227-236.

O’Brien, M., Margolin, G., \& John, R. S. (1995). Relation among marital conflict, child coping, and child adjustment. Journal of Clinical Child Psychology, $24,346-361$.

O'Leary, K. D. (1988). Physical aggression between spouses. In V. B. VanHasselt, R. L. Morrison, A. S. Bellack, \& M. Hersen (Eds.), Handbook of Family Violence (pp. 31-55). New York: Plenum Press.

Owens, D. J., \& Straus, M. A. (1975). The social structure of violence in childhood and approval of violence as an adult. Aggressive Behavior, 1, 193211.

Palace, E. M., \& Gorzalka, B. B. (1990). The enhancing effects of anxiety on arousal in sexually dysfunctional and functional women. Journal of Abnormal Psychology, 99, 403-411.

Quinsey, V. L., Chaplin, T. C., \& Upfold, D. (1984). Sexual arousal to nonsexual violence and sadomasochistic themes among rapists and non-sexoffenders. Journal of Consulting and Clinical Psychology, 52, 651-657.

Quinsey, V. L., Chaplin, T. C., \& Varney, G. (1981). A comparison of rapists' and non-sex offenders' sexual preferences for mutually consenting sex, rape, and physical abuse of women. Behavioral Assessment, 3, 127-135. 
Ray, A. L., \& Gold, S. R. (1996). Gender roles, aggression, and alcohol use in dating relationships. The Journal of Sex Research, 33, 47-55.

Riger, S., \& Gordon, M. T. (1981). The fear of rape: A study of social control. Journal of Social Issues, 37, 71-92.

Rosen, R. C., \& Beck, J. G. (1988). Patterns of sexual arousal: Psychophysiological processes and clinical applications. New York: The Guilford Press.

Rozee, P. D. (1993). Forbidden or forgiven? Rape in cross-cultural perspective. Psychology of Women Quarterly, 17, 499-514.

Russell, D. E. H. (1984). Sexual exploitation: Rape, child sexual abuse, and workplace harassment. Beverly Hills, CA: Sage Publications.

Russell, R. J., \& Hulson, B. (1992). Physical and psychological abuse of heterosexual partners. Personality and Individual Differences, 13, 457-473.

Saris, R. N. (1996). The influence of contemporary music on responses to visually presented mainstream sexually explicit images. (Doctoral dissertation, University of Rhode Island, 1996). Dissertation Abstracts International, 58, 1026B.

Schachter, S. (1964). The interaction of cognitive and physiological determinants of emotional state. In L. Berkowitz (Ed.), Advances in experimental social psychology, Vol. 1. New York: Academic Press, Pp. 49-80.

Schachter, S., \& Singer, J. (1962). Cognitive, social, and physiological determinants of emotional state. Psychological Review, 69, 379-399. 
Simpson, J. A., \& Gangestad, S. W. (1991). Individual differences in sociosexuality: Evidence for convergent and discriminant validity. Journal of Personality and Social Psychology, 60, 870-883.

Spaccarelli, S., Sandler, I., \& Roosa, M. (1994). History of spouse violence against mother: Correlated risks and unique effects in child mental health. Journal of Family Violence, 9, 79-98.

Stagg, V., Wills, G. D., \& Howell, M. (1989). Psychopathology in early childhood witnesses of family violence. Topics in Early Childhood Special Education, 9, 73-87.

Straus, M. A. (1983). Ordinary violence, child abuse, and wife-beating. In D. Finkelhor, R. J. Gelles, G. T. Hotaling, \& M. A. Straus (Eds.), The dark side of families: Current family violence research. Newbury Park, CA: Sage. Pp. 213234.

Straus, M. A., \& Gelles, R. J. (1990). Physical violence in American families: Risk factors and adaptations to violence in 8,145 families. New Brunswick, NJ: Tansaction.

Straus, M. A., Gelles, R. J., \& Steinmetz, S. (1980). Behind closed doors: Violence in the American family. New York: Anchor/Doubleday.

Straus, M. A., \& Yodanis, C. L. (1996). Corporal punishment in adolescence and physical assaults on spouses in later life: What accounts for the link? Journal of Marriage and the Family, 58, 825-841.

Struckman-Johnson, C. (1988). Forced sex on dates: It happens to men, too. Journal of Sex Research, 24, 234-241. 
Tedeschi, J. T., \& Felson, R. B. (1994). Violence, aggression, \& coercive actions. Washington, DC: American Psychological Association.

Weinberg, M. S., Lottes, I. L., \& Gordon, L, E. (1997). Social class background, sexual attitudes, and sexual behavior in a heterosexual undergraduate sample. Archives of Sexual Behavior, 26, 625-642.

Weis, D. L. (1998a). The use of theory in sexuality research. The Journal of Sex Research, 35, 1-9.

Weis, D. L. (1998b). Conclusion: The state of sexuality theory. The Journal of Sex Research, 35, 100-114.

White, J. W., \& Sorenson, S. B. (1992). A sociocultural view of sexual assault: From discrepancy to diversity. Journal of Social Issues, 48, 187-195.

Wincze, J. P., Hoon, P., \& Hoon, E. F. (1977). Sexual arousal in women: A comparison of cognitive and physiological responses by continuous measurement. Archives of Sexual Behavior, 6, 121-133.

Winfield, I., George, L. K., Schwartz, M., \& Blazer, D. G. (1990). Sexual assault and psychiatric disorders among a community sample of women. American Journal of Psychiatry, 147, 335-341.

Wolchik, S. A., Beggs, V. E., Wincze, J. P., Sakheim, D. K., Barlow, D. H., \& Mavissakalian, M. (1980). The effects of emotional arousal on subsequent sexual arousal in men. Journal of Abnormal Psychology, 89, 595-598.

Wolchik, S. A., Braver, S. L., \& Jensen, K. (1985). Volunteer bias in erotica research: Effects of intrusiveness of measure and sexual background. Archives of Sexual Behavior, 14, 93-107. 
Wolfe, D. A., Jaffe, P., Wilson, S. K., \& Zak, L. (1985). Children of battered women: The relation of child behavior to family violence and maternal stress. Journal of Consulting and Clinical Psychology, 53, 657-665.

Wormith, J. S. (1986). Assessing deviant sexual arousal: Physiological and cognitive aspects. Advances in Behaviour Research and Therapy, 8, 101137.

Zillman, D. (1979). Hostility and aggression. Hillsdale, NJ: Lawrence Erlbaum Associates.

Zillmann, D. (1984). Connections Between Sex and Aggression. Hillsdale, NJ: Lawrence Erlbaum.

Zuckerman, M. (1973). Scales for sexual experience for males and females. Journal of Consulting \& Clinical Psychology, 11, 27-29. 